\title{
Predicting the effects of anthropogenic noise on fish reproduction
}

\author{
Karen de Jong (D) Tonje Nesse Forland • Maria Clara P. Amorim • \\ Guillaume Rieucau • Hans Slabbekoorn - Lise Doksæter Sivle
}

Received: 28 February 2019/Accepted: 17 February 2020/Published online: 5 March 2020

(C) The Author(s) 2020

\begin{abstract}
Aquatic animals use and produce sound for critical life functions, including reproduction. Anthropogenic noise is recognized as a global source of environmental pollution and adequate conservation and management strategies are urgently needed. It becomes therefore critical to identify the reproductive traits that render a species vulnerable to acoustic disturbances, and the types of anthropogenic noise that are most likely to impact reproduction. Here, we provide predictions about noise impact on fish reproduction following a two-step approach: first, we grouped documented effects of noise into three mechanistic categories: stress, masking and hearing-loss, and test which type of noise (continuous vs intermittent and regular vs irregular) was most likely to produce a
\end{abstract}

Electronic supplementary material The online version of this article (https://doi.org/10.1007/s11160-020-09598-9) contains supplementary material, which is available to authorized users.

K. de Jong $(\bowtie) \cdot$ T. N. Forland · L. D. Sivle Institute of Marine Research, PO Box 1870, Nordnes, 5817 Bergen, Norway

e-mail: karen.de.jong@hi.no; karende@alumni.ntnu.no

M. C. P. Amorim

MARE - Marine and Environmental Sciences Centre, ISPA - Instituto Universitário, Lisbon, Portugal

Present Address:

M. C. P. Amorim

Department of Animal Biology, University of Lisbon, Lisbon, Portugal significant response in each category with either a metaanalysis or a quantitative review, depending on data availability. Second, we reviewed existing literature to predict which reproductive traits would render fish most sensitive to stress, masking and hearing-loss. In step one, we concluded that continuous sounds with irregular amplitude and/or frequency-content (e.g. heavy ship traffic) were most likely to cause stress, and continuous sounds were also most likely to induce masking and hearing-loss. From step two we concluded that the vulnerability of a species to noise-induced stress will mainly depend on: (1) its potential to reallocate reproduction to more quiet times or locations, and (2) its vulnerability to masking and hearing-loss mainly on the function of sound communication in its reproductive behaviour. We discuss in which stages of reproduction fish are most likely to be vulnerable to anthropogenic noise based on these findings.

\author{
G. Rieucau \\ Louisiana Universities Marine Consortium, 8124 \\ Highway 56, Chauvin, LA 70344, USA \\ H. Slabbekoorn \\ Behavioural Biology, Institute of Biology, Leiden \\ University, PO Box 9505, 2300 RA Leiden, The \\ Netherlands
}




\section{Graphic abstract}

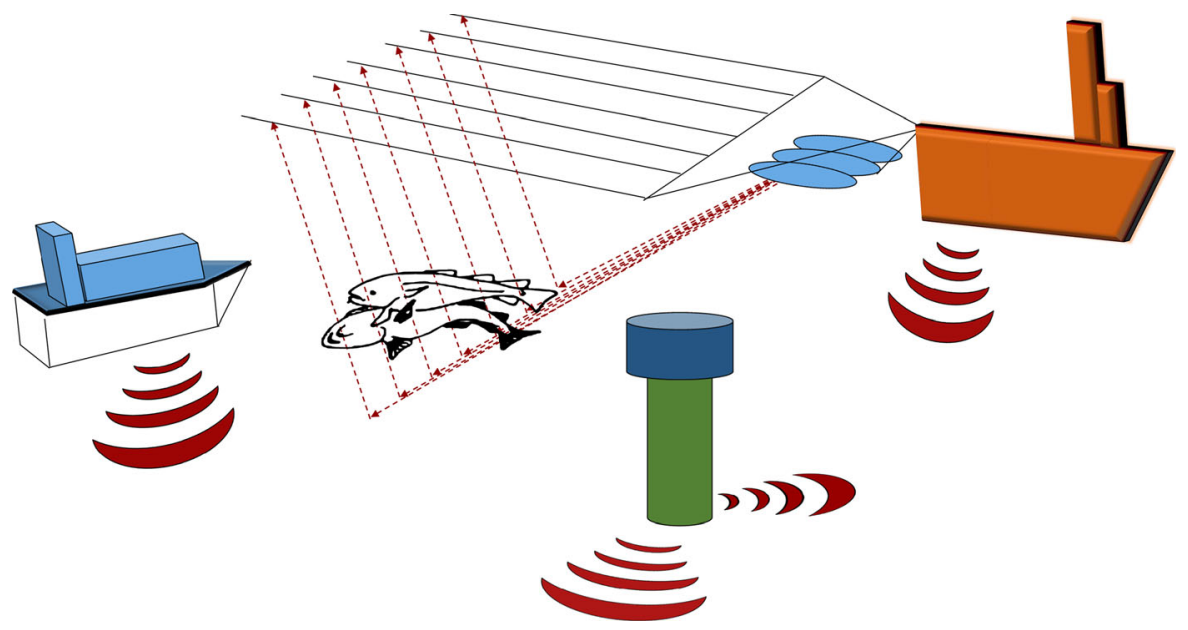

Keywords Impact assessment · Hearing-loss · Masking · Meta-analysis · Noise-induced stress · Sound types

\section{Introduction}

Anthropogenic noise pollution is a concern for human health and considered to be an important pollutant of terrestrial ecosystems (WHO 2011; Francis and Barber 2013; Shannon et al. 2016; Slabbekoorn et al. 2018). Recently, there is increased awareness about noisy human activities at sea, such as vessel traffic, seismic exploration of the sea bottom and construction work. There are few records of underwater anthropogenic noise measurements before 1990, but these show that ambient noise levels have increased by as much as $12 \mathrm{~dB}$ in 30 years in some parts of the ocean (Andrew et al. 2002; McDonald et al. 2006; Hildebrand 2009; Frisk 2012). Ocean noise-disturbance can affect the physical integrity (at exceptional exposure levels), physiology and behaviour of aquatic animals, which may affect individual fitness and may have population and ecosystem level consequences (New et al. 2014; Kunc et al. 2016; Slabbekoorn et al. 2019).

Sound production is taxonomically wide-spread in fishes, and may have evolved multiple times in different families (Fine and Parmentier 2015). Sound production plays an important role in fish reproductive success, as acoustic signals are often correlated with male qualities such as size and condition (e.g. de Jong et al. 2007; Amorim et al. 2013), which may affect female spawning decisions, and thus relate to mating success (Rowe and Hutchings 2006; Vasconcelos et al. 2012). Therefore, fishes that rely on acoustic communication may be the most obvious to be affected by anthropogenic noise (van der Sluijs et al. 2011; Radford et al. 2014). However, all fish have the capability to hear low-frequency sounds $(<500 \mathrm{~Hz})$ and, consequently, can be disturbed by noisy human activities (Popper et al. 2003, 2014).

General effects of noise on aquatic life have been reviewed extensively (e.g. Slabbekoorn et al. 2010; van der Sluijs et al. 2011; Popper et al. 2014; Radford et al. 2014; Williams et al. 2015; Kunc et al. 2016; Carroll et al. 2017; Hawkins and Popper 2017; Cox et al. 2018; Slabbekoorn et al. 2019). These reviews highlight a critical need for data on population level effects, including reproduction, as successful reproduction is essential for population viability. For many fish species, the spawning period may be highly sensitive to impacts from noise if individuals gather in dense, localized spawning aggregations (Colin et al. 2003). A disturbance during spawning may thus hamper a much larger fraction of the population compared to other periods of the year. Additionally, during this critical period, fish may also be most vulnerable to external stressors (Pörtner and Farrel 2008), because fish are often in their poorest body condition during the spawning period (Holst 2004; Rose et al. 2008). 
How anthropogenic noise affects reproductive success is species-specific and depends on the hearing ability and reproductive biology of the exposed species (Amoser and Ladich 2003; Hawkins and Popper 2017). Yet, some responses (e.g. at the genetic, cellular and physiological levels) will be shared across taxa and species (de Soto and Kight 2016; Cox et al. 2018), enabling more general predictions about potential impacts. As current knowledge is scattered across species and reproductive stages, there is a need for a thorough evaluation of published work to predict which species and stages of reproduction may be most sensitive to different types of noise-disturbance.

The aim of this study was to provide testable predictions for effects of different types of anthropogenic noise on fish reproduction. We categorized the potential effects of anthropogenic noise on reproductive behaviour in fishes into three main mechanisms: (1) stress, which can affect growth, maturation, and reproduction, but also signalling and avoidance behaviour; (2) masking of signals and acoustic cues, with potential impact on communication, feeding rate and predation; and (3) hearing-loss, such as elevated hearing thresholds and reduced temporal resolution leading to similar, but prolonged effects compared to masking (Fig. 1). Exposure to intense sounds can also lead to physical damage (e.g. barotrauma), but we excluded this from this review because it only occurs close to the sound source and thus only affects a small part of the population (Slabbekoorn et al. 2010; Kunc et al. 2016). Distraction was also excluded as a mechanism (Chan et al. 2010; Chan and Blumstein 2011), because there is currently no direct evidence that this plays a role in fish reproduction (but see Nedelec et al. 2017). In previous reviews (e.g. Kunc et al. 2016; Cox et al. 2018), effects of sound on fish have commonly been grouped into anatomical, physiological and behavioural responses. However, since most studies provide data on several such responses that are likely inter-correlated (e.g. physiological and behavioural stress-responses, or anatomical and physiological changes leading to hearing-loss), we decided to group effects based on the underlying mechanisms, rather than the types of responses (Fig. 1).

We approached the formulation of predictions in a two-step approach (Fig. 1). First, we conducted a meta-analysis using the available peer-reviewed literature on the topic to test what types of noise are most likely to affect the following three mechanisms: (1) stress, (2) masking and (3) hearing-loss in fish ("Methods for the meta-analyses" and "Results and discussion meta-analyses" sections; Fig. 1; Box 1). Second, we reviewed published work on how and when these three mechanisms could affect fish

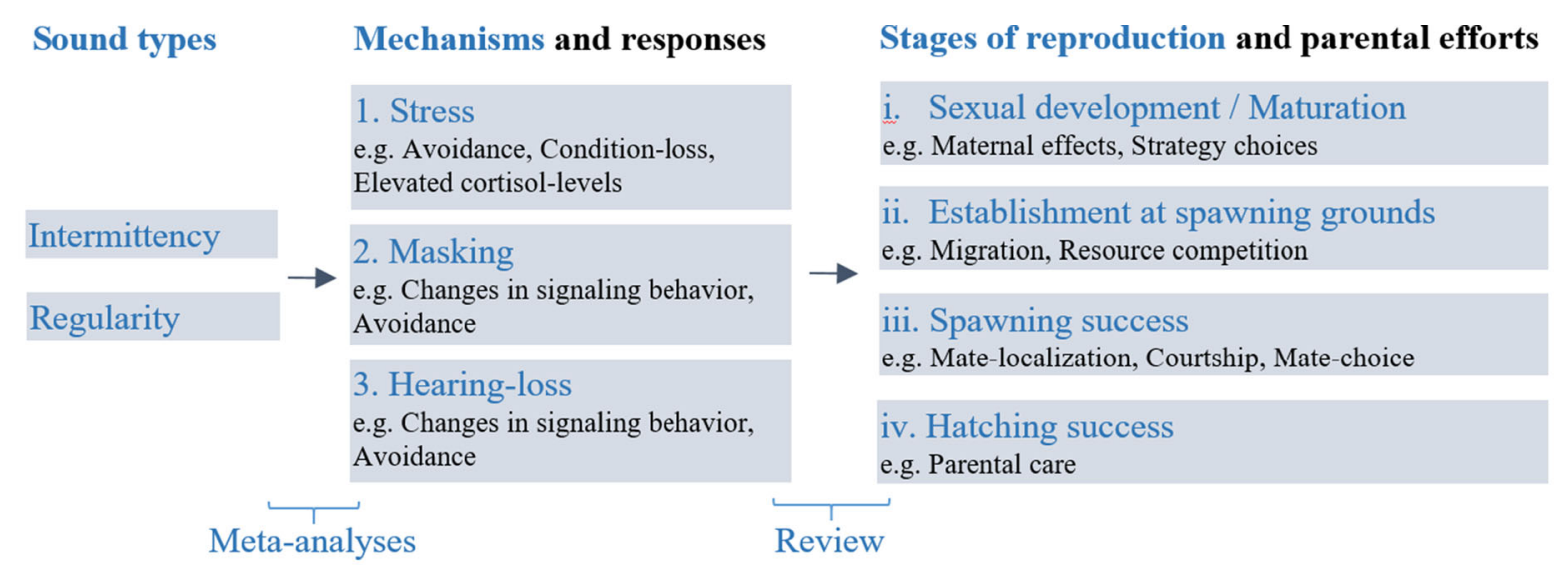

\section{Predicted effects of different sound types on different stages of reproduction (Table 4)}

Fig. 1 The two-step process used in this study to predict effects of noise on fish reproduction, using data on the effects of anthropogenic noise on stress, masking and hearing-loss, and known effects of stress, masking and hearing-loss on fish reproduction 
Box 1 Key concepts

Anthropogenic noise Any sound from a man-made source, typically: boats, construction work (pile-driving), wind turbines and seismic activity (Hildebrand 2009; Slabbekoorn et al. 2010)

Attention shifts Performance often depends on perceptual focus. Anthropogenic noise may distract animals and such attention shifts may undermine their performance in vital tasks, (Chan et al. 2010; Chan and Blumstein 2011)

Communication active space The volume around a signaller (see signal vs. cue) in which enough of the signal is audible to permit communication (Brenowitz 1982)

Hearing-loss Permanent or temporary loss of the ability to detect a sound or discriminate it from other sounds

Intermittent sound Any interrupted sound (non-continuous). Interruptions can happen on a relatively long temporal scale, i.e. several passages of boats, or a relatively short temporal scale, i.e. the separate firing of airguns in a seismic survey. In this review we will use the duration of the observed reproductive event or experimental exposure as the relevant time-scale

Irregular sound A sound with a non-uniform energy distribution over time, through irregularity in amplitude, frequency content, or in the timing of relatively quiet periods

Masking Masking occurs when ambient noise hampers the uptake of information from an acoustic signal or cue due to partial or complete overlap in the receiver's auditory system (Brumm and Slabbekoorn 2005)

Reproductive effort The proportion of an organism's resources (e.g. time and energy) devoted to reproductive processes

Signal versus cue We will use the biological definition of signal throughout this paper: An acoustic signal is a sound that is made by an animal (the sender) that is selected for its effects on the behaviour of another organism (the receiver), while an acoustic cue is any sound that contains information about the surroundings, which may stem from biotic or abiotic sources (BroJørgensen 2010; Bradbury and Vehrencamp 2011). This definition of signals and cues is not limited to the acoustic modality, because both signals and cues can exist in any of the sensory modalities, and combinations thereof (visual, chemical, etc.

Bradbury and Vehrencamp 2011)

Stress The physiological cascade of events that occurs when an organism is attempting to resist death or re-establish homeostatic norms in the face of disturbance (Schreck 2000)

reproduction ("Formulating predictions for effects of sound types on fish reproduction" section; Fig. 1). From these two steps, we formulated predictions on how different types of noise could affect the different stages of fish reproduction (Fig. 1) After we formulated these predictions, we tested whether the few currently published papers that directly examined effects of noise on fish reproduction supported them ("Qualitative test of predictions" section). The papers used for this test were not used in the meta-analyses that we used to formulate the predictions, because these papers reported effects of noise on fish reproduction directly rather than effects of noise on stress, masking and hearing-loss (Suppl. Table 2).

\section{Stress}

Stress is the physiological cascade of events occurring when organisms attempt to resist potentially lifethreatening situations or re-establish homeostasis in the face of disturbance (Schreck 2000; Schreck et al. 2016; Box 1). The primary response happens within seconds, and consists of a neurological and a hormonal response priming the animal for a fight-flight or freeze response (Wendelaar Bonga 1997). The secondary response is a term used to describe the activation of the hypothalamo-pituitary-interrenal axis, which triggers concentration changes in a suite of hormones, reflected and typically measured by increased blood-levels of cortisol, which peak within $15 \mathrm{~min}$ and may return to normal within $30 \mathrm{~min}$ if the stressor ends or habituation sets in (Romero and Butler 2007; Tudorache et al. 2015; Schreck et al. 2016). These stages of stress are normal responses to deviations from homeostasis, and hence not necessarily costly (Barton 2002). However, if stress is prolonged, the tertiary response may set in, which often is mal-adaptive (distress; Schreck et al. 2016). The latter concerns chronic stress and may induce physiological changes, such a decrease in body condition, reduction in growth, and a hampered immune system (Sapolsky et al. 2000; Romero and Butler 2007). After 2-3 weeks of continuous stress, reproductive physiology may also be impaired (Deak 2007; Schreck and Tort 2016). Free-ranging fish can avoid stressors to some extent, but such avoidance could carry other costs, such as lost feeding or spawning opportunities (Schreck 2010). 
Masking

Anthropogenic noise can overlap in frequency and time with a sound of interest (signal or cue) and render it less audible to the receiver (Box 1). The level of masking is determined by the extent of frequency overlap and amplitude of the masking sound relative to the signal or cue at the receiver. Sounds that do not directly overlap, but are similar in frequency or timing, can still mask each other if the perceptual resolution in the auditory system of the receiver is unable to distinguish the sounds (Bro-Jørgensen 2010; Dooling et al. 2015). However, animal auditory systems also have adaptations that can prevent masking (Ladich 2013). For example, release from masking can occur when sound sources are located at different angles from the receiver ('spatial release') or if masked frequencies co-modulate with frequencies that are not masked (Brumm and Slabbekoorn 2005; Erbe et al. 2016). Alternatively, communication signals may be tuned to relatively quiet spectral or temporal windows in the habitat-specific ambient noise (Crawford et al. 1997; Lugli 2010; Amorim et al. 2018).

The detection threshold is the minimum level at which a sound is audible to a receiver within the background of noise. In the event a sound is detected, incomplete masking can impair the ability to recognize acoustic details and distinguish between particular sounds, thus hampering effective communication (Pollack 1975; Clark et al. 2009; Dooling et al. 2015). The calculation of thresholds for comfortable hearing requires more detailed knowledge of the auditory system than the calculation of detection thresholds (Dooling et al. 2000; Erbe et al. 2016). Such data are largely lacking for fish and we are aware of only one study on comfortable communication thresholds. This study found that conspecific signals were accurately represented in the brain when played back at a level comparable to received levels from a fish calling at up to $13 \mathrm{~m}$ distance (Alves et al. 2016). Animal auditory systems also have adaptations that can reduce masking (Ladich 2013). For example, release from masking can occur by exploiting acoustic variation due to sound sources being located at different angles from the receiver ('spatial release') or because masked frequencies co-modulate with frequencies that are not masked (Brumm and Slabbekoorn 2005; Erbe et al. 2016). Alternatively, communication signals may be tuned to relatively quiet spectral or temporal windows in the habitat-specific ambient noise (Crawford et al. 1997; Lugli 2010).

Hearing-loss

High intensity acute noise (e.g. pile driving or seismic airguns), as well as prolonged exposure to lower intensity noise (industrial noise, aquaculture facilities) can cause temporary or permanent hearing-loss (TTS or PTS; Amoser and Ladich 2003, McCauley et al. 2003; Scholik and Yan 2001) and impaired temporal resolution (Wysocki and Ladich 2005; Box 1). Species with enhanced hearing abilities may be more affected by noise than fish that do not have such adaptations (Amoser and Ladich 2003). Hearing-loss, just like masking, reduces the ability of a receiver to perceive sounds. However, it involves a physiological or anatomical change in the animal, and could therefore have more prolonged effects. Although hair cells damaged by overexposure may regenerate in fish (Corwin and Oberholtzer 1997; Smith et al. 2006; Monroe et al. 2015), days or weeks with reduced hearing may lead to missed reproductive opportunities.

\section{Methods for the meta-analyses}

Terminology

Stages of reproduction

Reproduction can be organized into four distinct stages: (1) the development of primary and secondary sexual characteristics; (2) the arrival and establishment at spawning grounds; (3) spawning, including mate attraction and mate choice; and (4) parental care/ hatching (Fig. 1). Parental investment in each of these stages may have physiological and behavioural components, but it always requires energy. In each of the four stages, animals have to find and compete for resources (i.e. suitable habitat, nesting material, mates), which may involve the exploitation of acoustic cues from the environment and communication with acoustic signals (Amorim 2006). Changes in parental behaviours or physiology due to anthropogenic noise may affect reproduction in each of the phases. 


\section{Types of anthropogenic noise}

Different sources of anthropogenic noise may result in highly different sound fields; hence it becomes essential to understand which sound types disturb fish most to develop appropriate management and mitigation practices. Vessel sound, for example, is considered the most widespread source of continuous anthropogenic noise underwater, and it may totally dominate the low-frequency soundscape in heavily trafficked areas (Haviland-Howell et al. 2007; Stanley et al. 2017; Sertlek et al. 2019; Suppl. Table 1). The passage of a single vessel will be characterized by a wideband sound with a few dominating tonal (narrowband) components varying in amplitude and frequency (Ogden et al. 2011; McKenna et al. 2012;
Fig. 2a). Continuity of the sound depends on the number of vessels passing an area, but even continuous traffic produces irregular fluctuations in amplitude (Sertlek et al. 2019). Seismic explorations are a major source of anthropogenic noise in marine systems due to their high source level (Hildebrand 2009, Gisiner 2016; Suppl. Table 1). During a survey an array of airguns releases compressed air into the water producing short, broadband, high amplitude sound pulses at regular intervals (Fig. 2b). The pulse duration, the sound envelope and the dominant frequencies can change with distance (Fig. 2b). Typically, large areas are investigated during several weeks along transects that can span over hundreds of kilometres (Gisiner 2016). As a result, a stationary fish may experience varying levels of continuity and
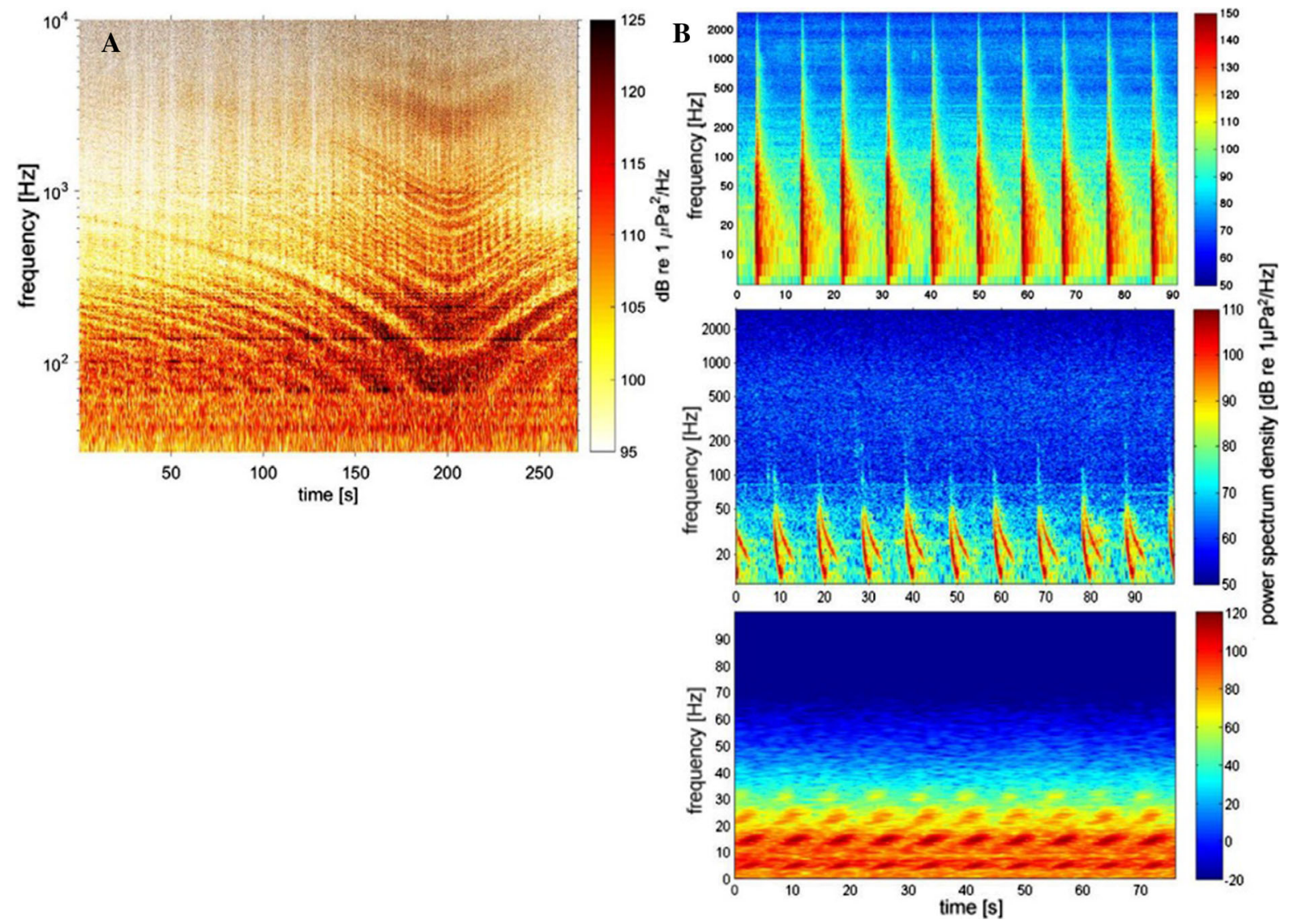

Fig. 2 a A passing boat recorded a at $34 \mathrm{~m}$ depth, showing tonal components and changes in amplitude and frequency, which will create irregular sound patterns if several vessels pass. b Seismic sound at $1.5 \mathrm{~km}$ (top), $80 \mathrm{~km}$ over a soft sea bed in shallow water, and $40 \mathrm{~km}$ over a hard sea bed in shallow water, showing that the received sound from a seismic survey can be

intermittent to continuous depending on distance to the source and properties of the ocean floor, but is always regular. (Re-used with permission from Erbe et al. (2016). Communication masking in marine mammals: A review and research strategy. Marine Pollution Bulletin 103 15-38, Elsevier 2016) 
regularity as the survey progresses. Pile driving produces the most pervasive sound during construction of new structures (wind farms, oil platforms; Madsen et al. 2006; Suppl. Table 1). The hammer strokes produce brief, high amplitude, broadband pulses at a single location, but sound waves may enter the seafloor, and propagate along the water/bottom boundary and be reflected and/or refracted back into the water column in other locations (Hazelwood and Macey 2016). Pile-driving will thus likely produce a less regular pattern of intermittent sounds than a seismic survey.

Dominate sound sources may vary between different areas, and may include other sources of low frequency sound than those examined here (e.g. drilling, dredging, low frequency military sonars, explosions, and land traffic, e.g. Hildebrand 2009; Holt and Johnston 2015; Marley et al. 2016). Sound propagation depends on the source level and environmental conditions like water depth, bathymetry, sediment and water properties, and surface roughness (Farcas et al. 2016). Therefore, the sound from these sources that reaches fish spawning grounds may vary in acoustic characteristics, such as intermittency, regularity, length of exposure and sound pressure level (Box 1; Fig. 2). In this study, we focus on the effects of continuity and the regularity of the sounds sources (Box 1).

\section{Fish hearing and experimental exposure to sound}

Most fish hear best below $500 \mathrm{~Hz}$ by sensing particle acceleration with their inner ear (Popper and Fay 2011). Some fish can hear higher frequencies, including the ultrasound range (e.g. herring; Enger 1967; Popper and Fay 2011; Narins et al. 2013), by sensing pressure changes in their swim bladder, especially if it is connected to the inner ear (Chapman and Hawkins 1973; Bretschneider et al. 2013, Popper and Hawkins 2018). The lateral line may also be involved in sensing lower frequencies (Higgs and Radford 2012). The particle acceleration that mainly excites the fish hearing system will not be linearly related to the measured sound pressure in most laboratory environments (Parvulescu 1967; Hazelwood and Macey 2016; Nedelec et al. 2016; Popper and Hawkins 2018). Therefore, the measured pressure levels in the experiments may not accurately reflect the levels experienced by the fish under study. However, if one uses the same experimental set-up for comparisons between different sound levels (e.g. ambient vs exposure), it is reasonable to assume that an increase in measured sound pressure will reflect an increase in particle displacement, because both are a direct result of an increase in the intensity of the sound. Thus, while laboratory studies are not suitable to provide information on absolute sound levels for fish responses in their natural habitat, they can provide information on whether certain sound types are more likely than others to affect fish.

Hypotheses and predictions prior to the metaanalyses

Different sound types may affect stress, masking and hearing in different ways. For example, irregular sound will be less predictable than regular sounds (Box 1), and unpredictable stressors may induce higher levels of stress than more predictable stressors (Wingfield and Ramenofsky 1999; Wright 2007; Galhardo and Oliveira 2009; Galhardo et al. 2011). We therefore hypothesized those irregular sounds would affect stress in fish more than regular sounds, although particularly intense sounds may cause stress regardless of predictability. In the case of intermittent sound, each repeated onset of sound may produce repeated startle response until habituation sets in. We thus expected an increased stress response for intermittent vs. continuous sound for short exposures, which may or may not translate to a long-term impact on chronic stress. For masking, on the other hand, we expected that animals could use intermittencies as opportunities for communication, and therefore continuous sound would be more problematic. We expected hearing-loss to be affected mainly by the intensity, but also by the length of the sound-exposure.

\section{Literature search}

We exploited information in the literature for a metaanalysis to test which sound types were most likely to affect fish stress, masking and hearing ability. We searched for [("anthropogenic noise" or "pile driv*" or seismic or "boat* noise" or "aquatic noise" or "underwater noise" or "noise exposure") and (fish or fishes)] [last search 18-01-2018] in web of science. With these search terms we found 405 papers, we excluded 28 reviews and 15 other (news items etc.) 
that were not original data reports, leaving 359 research articles. Furthermore, we excluded 38 conference proceedings, because they were not peerreviewed, leaving 320. We excluded a further 108 papers based on the abstract, and 100 papers based on the full text, because they did not provide data on the effects of noise on fish, leaving us with 112 topical papers with relevant data. We included all studies that provided a statistical test on differences in stress masking or hearing ability between treatments, periods or sites with vs without increased noise levels. Furthermore, we cross-checked the references in these 112 papers for additional papers that may have been missed in our initial web-of-science search, and found a further 21 papers, leading to a total of 133 .

\section{Statistical analyses}

We conducted three separate test to assess which sound type was most likely to affect (1) stress, (2) masking and (3) hearing-loss in fish. To test effects of noise on stress, we divided stress responses into physiological responses using tests on effects of noise on cortisol, ventilation and metabolic rates, and behavioural responses using tests on effects of noise on startle or freeze behaviours (emergency response), horizontal and vertical avoidance (or dive-down; generally measured as instantaneous changes in swimming depth). To test effects of noise on masking, we used reported comparisons of hearing thresholds with and without elevated noise levels during exposure, and to test effects of noise on hearing-loss, we used reported comparisons of post-exposure hearing thresholds in control vs. exposed individuals. Of the 133 considered studies, 62 reported one or more of these measures (see Suppl. Table 2).

We classified exposures as intermittent or continuous solely based on temporal characteristics: whether the sound exposure was interrupted (or not) during the experimental or observation period. Whether we classified a study as regular or irregular depended both on temporal and spectral characteristics: Within continuous sounds, we classified artificial sounds (white noise or linear sweeps) as regular. We classified boat noise as irregular, because of their variations in amplitude, spectral characteristics and temporal characteristics over time. However, some studies exposed animals to continuous repeats of a short recording of vessel noise, which would be more regular than longer recordings of varying vessel passages. We classified the exposures reported in eight studies that used boat noise playbacks as regular, due to a very high number of repeats ( $>$ 50: Scholik and Yan 2002; Liu et al. 2013; Nedelec et al. 2016; Radford et al. 2016), the use of a very short recording ( $<20 \mathrm{~s}$; Vasconcelos et al. 2007; Picciulin et al. 2010; Sebastianutto et al. 2011) or repeats of a single recording of one ship (Voellmy et al. 2014; Suppl. Table 2). Within intermittent sounds, we classified sounds as regular or irregular based on temporal regularity. We excluded sound level from the analyses, because it was not feasible to compare sound exposure levels between studies in a robust way. This was due to the non-linear relation between particle motion and pressure discussed above (Sect. 2.1.3) and due to differences in the frequencyband and time over which sound levels were quantified. In addition, differences in hearing thresholds of the tested species will affect the experienced sound levels in the treatments (Popper et al. 2014).

We tested the effect of intermittent versus continuous noise and regular vs. irregular noise, as well as the interaction between intermittency and regularity on the likelihood that a significant effect was found on measures of stress, masking and hearing-loss using general linear models with a binomial error-structure in $\mathrm{R}$ version 3.5.0 (lme4 package; Bates et al. 2015; R Core Team 2017). Thus, our response variable was binary: whether or not a significant effect was found for each measure reported, while study was included as a random factor in the models. As covariates we included exposure length, type of study: laboratory vs field studies, habitat: freshwater vs marine species, and stage: adults vs juveniles. Because exposure time was very unevenly distributed, we converted it to an ordered factor with four levels: "minutes" (less than an hour), "hours" (1-23 h), "days" (more than one day), and "months" (more than a month) to include it in the models.

Due to the still limited number of studies available, we were unable to include all covariates in the full model. Therefore, we included covariates one by one and selected the model that fitted the data best on the basis of AICc (AICcmodavg package; Mazerolle 2017). AICc is an adaptation of Akaike's information criterion (AIC; Akaike 1973) for small sample sizes (Sugiura 1978; Hurvich and Tsai 1991). The datapoints in the model were weighed by the sum of the sample size of the treatment and the sample size of the control. In this way, repeated measure studies were 
weighed similarly to independent tests, because we assumed that the precision of repeated measure studies was higher than independent group studies for the same sample size (c.f. Morris and DeShon 2002).

We used the likelihood of a significant effect instead of effect sizes for three reasons. Firstly, we refrained from comparing a measure of variation across species and different types of noise, because variations in physiological parameters are known to be species-specific, and the limited data available for each species renders it impossible to test for effects within species. Secondly, we could not reliably compare sound levels between studies, and sound levels are likely to influence effect size. Thirdly, using effect sizes would have made it impossible to include different measures in the same model (Morris and DeShon 2002), which would have decreased samplesize. We assumed that the likelihood of a significant effect would be less sensitive to variations in effects between species and measures than analyses of effect sizes would be. By testing whether the type of study (laboratory vs field) had a significant effect on the results, we tested whether our findings were general rather than confined to either the laboratory or the field.
Because we used a binary score of a significant result vs a non-significant result, we could not test for publication bias in the usual way. Overall, we found 58 studies reporting at least one significant effect compared to 4 studies reporting no significant effects, thus $94 \%$ of the published studies reported at least one significant effect. Within these 62 published studies, we found that 159 of 227 tests $(70 \%)$ produced a significant effect. This would suggest that there likely is a publication bias towards significant effects, but this bias is less strong for the number of tests (which we used as dependent in the analyses) than for the number of studies. However, our main question was whether some sound types produced more significant effects than others, and we assumed that there was no difference between the sound types in publication bias.

\section{Results and discussion meta-analyses}

Types of noise and stress

We found 42 tests in 17 studies on 13 species of 9 families on physiological measurements of stress (cortisol: $\mathrm{N}=21$, ventilation rate: $\mathrm{N}=17$, metabolic

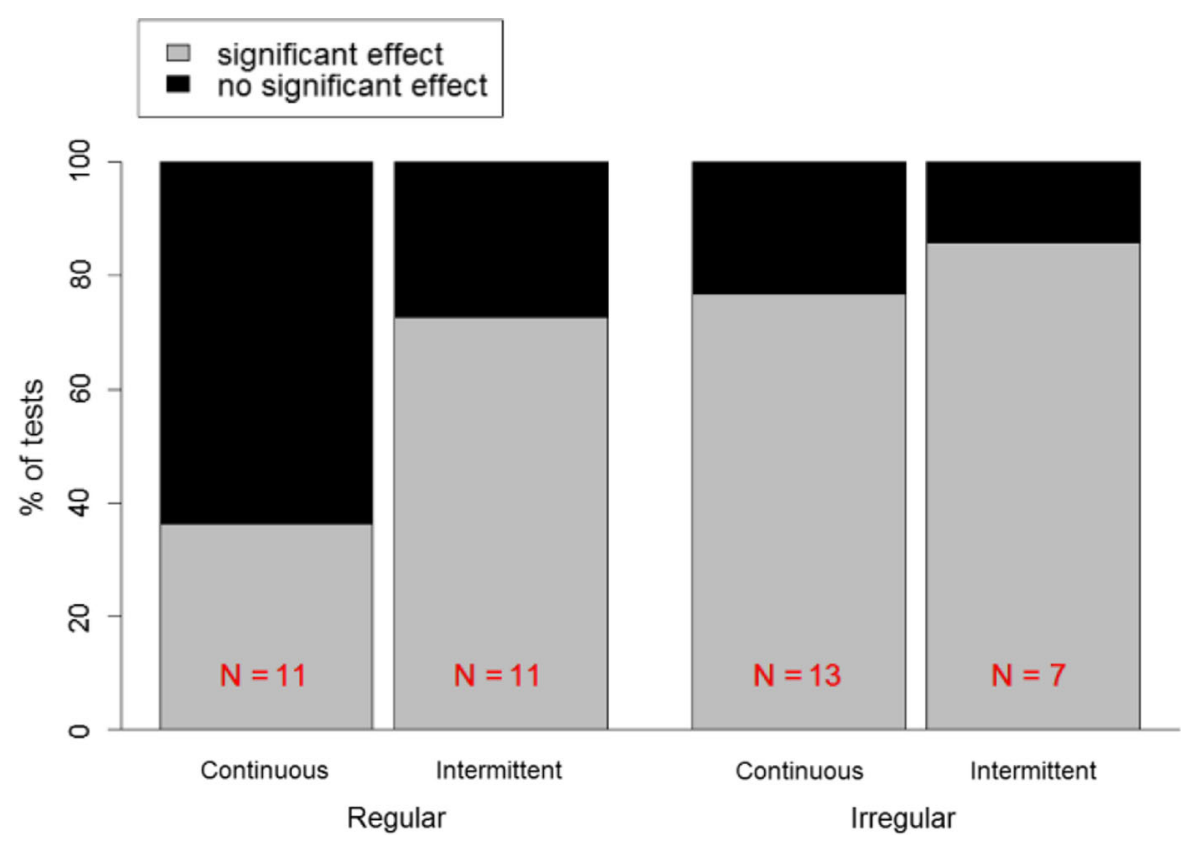

Fig. 3 The percentage of published tests on effects of different types of noise on physiological indicators of stress that were significant $(P<0.05)$ versus non-significant. Measures used: cortisol levels, ventilation rates, metabolic rates. In the

statistical model, we tested the likelihood of a significant effect based on binary scores, i.e. whether or not a significant effect was found for each test in each category, using study as a random factor 
Table 1 Outcome of binomial GLMM on effects of different sound characteristics on the likelihood of a significant effect of exposure on physiological measurements of stress

\begin{tabular}{lrrrrl}
\hline Fixed effects & Estimate & SE & $z$ & $P$ & $95 \%$ CI \\
\hline A. Number of observations: 42, random factor & groups: Study: N $=17$ & \\
(Intercept) & 10.54 & 3.33 & & & \\
Regular versus irregular & -1.83 & 0.32 & -5.78 & $<0.0001$ & -2.46 to -1.22 \\
Intermittent versus continuous & -3.92 & 1.68 & -2.34 & 0.019 & -10.26 to -1.56 \\
Interaction & 6.71 & 1.70 & 3.94 & $<0.0001$ & 4.25 to 13.06 \\
B. Number of observations: 37, random factor & groups: Study: N = 15 & \\
(Intercept) & 33.32 & 8.19 & & & \\
Regular versus irregular & -21.72 & 6.65 & -3.27 & 0.001 & - Inf to -12.59 \\
Intermittent versus continuous & -5.36 & 3.05 & -1.76 & 0.08 & -36.82 to -2.08 \\
Days versus minutes of exposure & -19.38 & 4.51 & -4.29 & $<0.0001$ & -44.64 to -11.81 \\
Interaction & 27.45 & 7.75 & 3.54 & 0.0004 & 16.29 to 79.95 \\
\hline
\end{tabular}

rate: $\mathrm{N}=4$ ). Stress was significantly affected by noise exposure treatment in 28 of these tests (Fig. 3). We found a significantly negative effect of regularity and intermittency, as well as a significant interaction of regularity and intermittency on the likelihood of a significant outcome (Table 1a). However, when we included exposure time in the model, excluding two studies that did not report this measure, only the effect of regular vs irregular and the interaction effect remained significant, even though the confidence interval of the effect of intermittency did not include zero, suggesting a negative effect of intermittency as well (Table 1b). Exposure time had a negative effect on the likelihood of a significant outcome, which may indicate a decrease of noise impact with habituation. When comparing both models on the same data, the model including exposure time fitted significantly better than the model without (AICc 304 vs 853); however, the confidence intervals of the model including exposure time included infinity which suggests that the model may be too heavy for the data. Because 5 of the 6 field studies found a significant effect of noise, regardless of type of noise, it was not possible to test whether the type of study affected the outcome. None of the other covariates led to a significant improvement of the model (AICc: none: 1058, habitat: 1060, stage: 1061). Overall, irregular sounds were more likely to affect physiological stress (Fig. 3).

We found 89 tests from 25 studies on 20 species of 14 families on behavioural measurements of stress [startle behaviours: $\mathrm{N}=36$, horizontal avoidance: $\mathrm{N}=24$, and vertical avoidance (instantaneous changes in swimming depth): $\mathrm{N}=29$ ]. Overall, 57 of these tests were significant versus 32 not significant (Fig. 4). We found a significantly negative effect of the intermittency and a significant interaction between regularity and intermittency on the likelihood of a significant outcome (Table 2, Fig. 4a). Irregular continuous sound was most likely to affect stress behaviours and irregular intermittent noise was least likely to affect stress behaviours (Fig. 4a). This pattern may be caused by a combined effect of intermittent sounds on startle behaviours (Fig. 4b), and irregular continuous sound on avoidance behaviours (Fig. 4c, d), though caution is warranted due to small sample size regarding the effect of irregular noise for startle responses. Of the 25 studies used in our analysis, $9(36 \%)$ did not report exposure length, limiting our ability to test this factor. Including other co-variates did not significantly improve the model (AICc: none: 1711, type of study: 1712, habitat: 1713, stage: 1713).

As hypothesized, we found that irregular sounds were more likely to affect both physiological and behavioural indicators of stress than regular sounds. Contrary to our expectations, our results showed that continuous sounds were more likely to affect stress than intermittent sound. Thus, continuous irregular sounds were most likely to have a significant effect on behavioural and physiological stress responses. This effect appeared to be most pronounced in the context of avoidance behaviours (Fig. 4c, d), while intermittent sounds may be more likely to lead to startle and freeze responses. The stronger effect of sound irregularity is consistent with an overall stronger effect of 

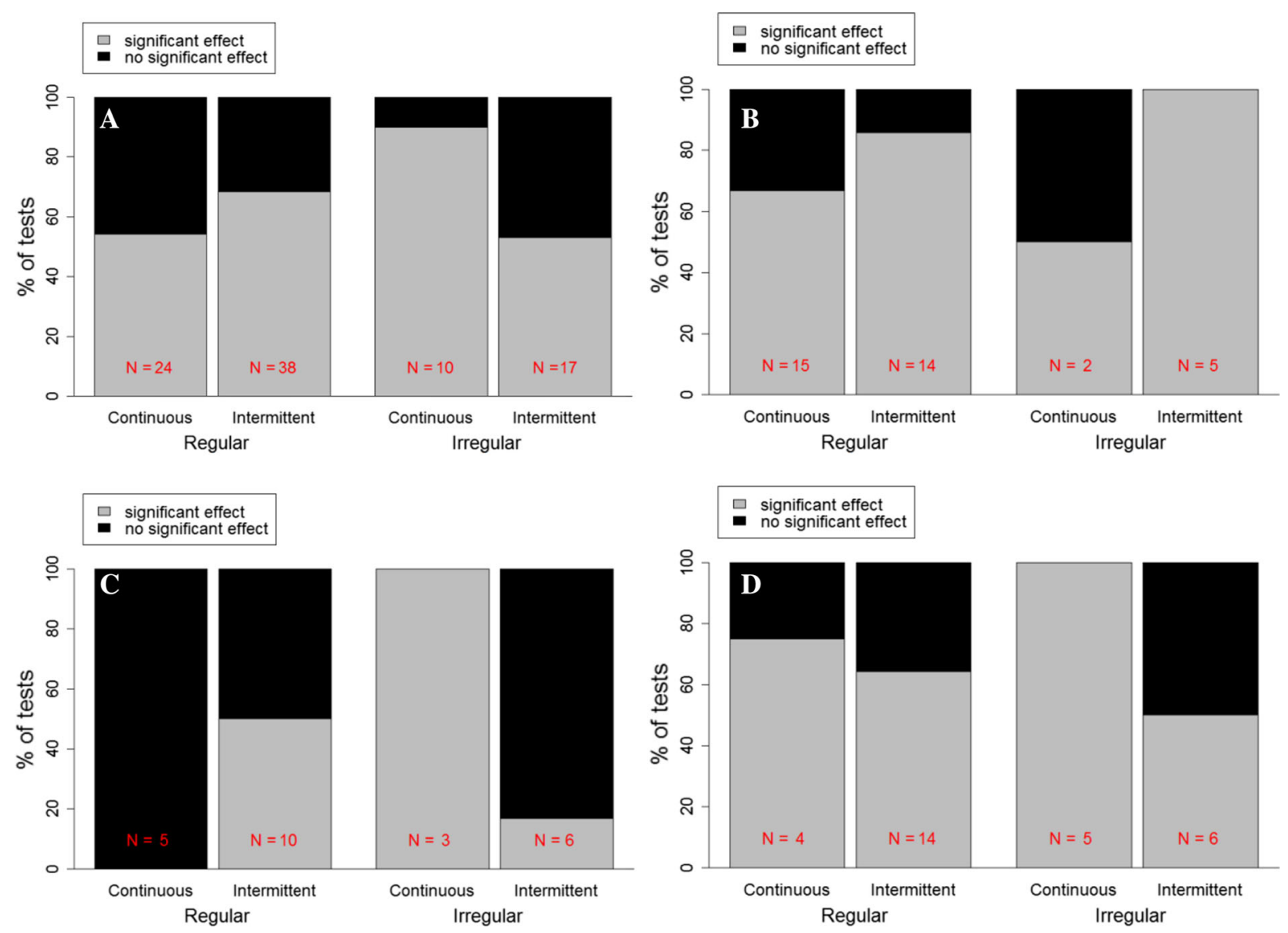

Fig. 4 The percentage of published tests on effects of different types of noise on behavioural indicators of stress that were significant $(P<0.05)$ versus. non-significant. Measures used: a all combined, b startle and freeze responses, c horizontal

avoidance, $\mathbf{d}$ vertical avoidance. In the statistical model, we tested the likelihood of a significant effect based on binary scores, i.e. whether or not a significant effect was found for each test in each category, using study as a random factor

Table 2 Outcome of binomial GLMM on effects of different sound characteristics on the likelihood of a significant effect of exposure on behavioural measures of stress

\begin{tabular}{lccccc}
\hline Fixed effects & Estimate & SE & $z$ & $P$ & $95 \%$ CI \\
\hline Number of observations: 89 , random factor groups: Study: $\mathrm{N}=25$ & 7.67 & 4.66 & & & \\
(Intercept) & -0.66 & 0.34 & -1.96 & 0.05 & -1.33 to 0.00 \\
Regular versus irregular & -1.05 & 0.36 & -2.93 & 0.003 & -1.76 to -0.35 \\
Intermittent versus continuous & 1.45 & 0.46 & 3.16 & 0.002 & 0.55 to 2.35 \\
Interaction & & & & & \\
\hline
\end{tabular}

anthropogenic noises when compared to pure tones on fish behaviour and physiology found in a recent metaanalysis (Cox et al. 2018), because anthropogenic noise is highly likely to be more irregular than tones. We found no evidence for differences between laboratory and field studies the likelihood of different sound types to affect behavioural stress responses, suggesting that these responses are possible to detect in the laboratory. For instance, horizontal avoidance has been detected in experimental set-ups where the size of the enclosure was suitably large relative to the size of the fish (Romine et al. 2015; Vetter et al. 2015, 2017; Shafiei Sabet et al. 2016). 
Types of noise and masking

We found 12 tests in 6 laboratory studies that directly explored the effects of sound-exposure on hearing thresholds (during exposure) in 10 species of fish, all using continuous noise, both regular $(\mathrm{N}=8)$ and irregular $(\mathrm{N}=4)$. All studies reported a significant increase in hearing thresholds regardless of whether the exposure was regular or irregular. In these studies fish were exposed to vessel noise, white noise and, in one case, aquaculture noise (Gutscher et al. 2011).

The presence of a significant effect in all studies precluded the use of a meta-analysis but suggested a consistent detrimental effect of continuous noise on masking. Publication bias may have caused this predominance of significant effects in the literature. However, biologically important sounds may be less masked than the tones used for establishing hearing thresholds (Vasconcelos et al. 2007; Belanger et al. 2010). This could potentially be due to the more complex structure of such sounds, which would reduce overlap, and would allow for perceptual adaptations that tune the auditory system of the receiver to biologically relevant sounds (Brumm and Slabbekoorn 2005; Erbe et al. 2016). In addition, the set-up to measure the effects of masking on hearing thresholds may not allow for spatial release from masking, due to the proximity of the speakers, and the associated unpredictability of the direction of particle motion close to the sound source, which could impair directional hearing (Popper and Hawkins 2018).

Due to species-specific differences in hearing systems, predicting what sound types and sound levels will mask communication in different species remains a challenging task (Ladich 2013; Dooling et al. 2015; Popper and Hawkins 2018). Vessel noise can cause strong masking effects even in fish with poorer hearing abilities (Vasconcelos et al. 2007; Codarin et al. 2009). Generally, the most important acoustic feature affecting the extent of masking is the level of acoustic energy in the frequency band of the signal (Dooling et al. 2015). Therefore, fish that use low-frequency communication signals, e.g. cod (Rowe and Hutchings 2006), are more likely to be affected by anthropogenic noise than fish that use high-frequency signals, such as herring (Wahlberg and Westerberg 2005; Wilson et al. 2004). In addition, we can assume that continuous noise will be most effective in masking communication, while intermittency may offer some release from masking (Dooling et al. 2000; Brumm and Slabbekoorn 2005).

Types of noise and hearing loss

We found 41 tests in 13 studies on 13 fish species from 10 families on the effects of noise on hearing

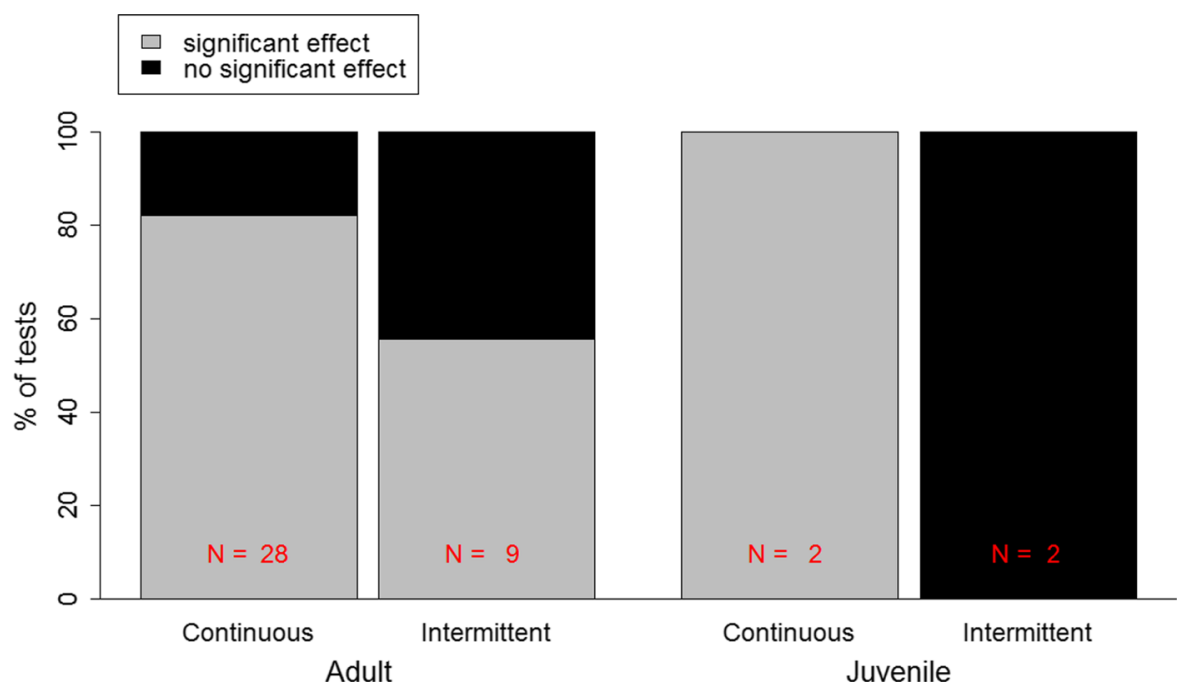

Fig. 5 The percentage of reported test on effects of different types of noise on hearing thresholds that were significant $(P<0.05)$ versus non-significant. All tests used regular noise. In the statistical model, we tested the likelihood of a significant

effect based on binary scores, i.e. whether or not a significant effect was found for each test in each category, using study as a random factor 
Table 3 Outcome of binomial GLMM on effects of different sound characteristics on the likelihood of a significant effect of exposure on hearing thresholds

\begin{tabular}{|c|c|c|c|c|c|}
\hline Fixed effects & Estimate & SE & $z$ & $P$ & \\
\hline \multicolumn{6}{|c|}{ Number of observations: 41 , random factor groups: Study: $N=13$} \\
\hline (Intercept) & 10.28 & 2.92 & & & \\
\hline Intermittent versus continuous & -10.71 & 7.34 & -1.46 & 0.14 & -35.75 to 8.08 \\
\hline
\end{tabular}

thresholds after the end of exposure (Fig. 5). Significant effects of noise on hearing-loss were found in 31 of these tests $(76 \%)$. Although these studies were all conducted on freshwater fish, hair cell damage due to noise exposure has also been reported in several marine species (McCauley et al. 2003). Only one of the 13 studies used irregular sound, which was, therefore, excluded. Intermittent sounds seemed less likely to cause a threshold shift than continuous sounds, but this effect was not significant (Table 3). Including the exposure time did not improve the model significantly (AICc: without: 130 vs with: 135). Only one study used marine fish and only two used juveniles, precluding the inclusion of habitat and stage in the model. Including type of study did not significantly improve model fit (AICc: without: $180 \mathrm{vs}$ with: 182), indicating no significant difference between lab and field studies. Our data thus suggest that continuous sound may have the potential to do more damage than intermittent sound. This may be due to the more rapid accumulation pf sound exposure level or the absence of recovery periods during exposure to continuous sound. During exposure to an intermittent sound, fish may be able to (partly) recover from noise-exposure after each sound burst, because fish are capable of rapid recovery of hearing structures, with a potential for full recovery within days after exposure (Smith et al. 2006).

\section{Formulating predictions for effects of sound types on fish reproduction}

The results of our meta-analyses show that stress and communication are most likely to be affected by continuous sound. In addition, stress is most likely to be affected by irregular sound. To formulate predictions on how continuous and irregular sound can affect different stages of reproduction, we reviewed published work, about how stress and the masking of signals and cues can affect reproduction, with a focus on recent reviews. A complete overview of our predictions is given in Table 4 .

Predicted effects of stress on reproduction

\section{Effects of stress on sexual development}

Reproduction is sensitive to stress, because cortisol generally inhibits the reproductive axis in favour of functions that increase the likelihood of survival. A particularly relevant terrestrial example of such an effect is the 10-year cycle of snowshoe hares (Lepus americanus, Leporidae), where the main factor explaining a decreased reproduction in years of a declining population size was found to be chronic stress from predation risk (Boonstra et al. 1998). In general, elevated levels of cortisol inhibit growth and reproduction (Schreck et al. 2001). However, there are exceptions: individuals that have a short time span to mate, such as older individuals, and individuals of semelparous or short-lived species, reproduce even when they experience high levels of cortisol (Wingfield and Sapolsky 2003). The timing of the stressor in reproduction may also be important: stress that occurs late in vitellogenesis may induce early spawning, while stress that occurs early may lead to postponement (Schreck et al. 2001; Skjæraasen et al. 2012). Overall, there seems to be a general pattern that species and individuals that have the opportunity to postpone spawning may be more likely to be affected by stress than species or individuals that do not have the opportunity to postpone spawning.

\section{Effects of stress on settlement on spawning grounds}

A typical response to stress is avoidance of the stressor (Schreck 2010). During migration, this can lead to delayed arrival at the destination (Rossington et al. 2013). In addition, stress could reduce energy 
Table 4 Predictions for the effects of different types of anthropogenic noise on fish reproduction derived from a meta-analysis on different types of anthropogenic noise on stress, masking and hearing-loss and a review of recent literature on how stress, masking and hearing-loss could affect fish reproduction

\begin{tabular}{|c|c|c|c|c|c|}
\hline $\begin{array}{l}\text { Sound type } \\
\text { most likely to } \\
\text { affect }\end{array}$ & Mechanism & Response & $\begin{array}{l}\text { Vulnerable } \\
\text { stages }\end{array}$ & Potentially affected parental effort & $\begin{array}{l}\text { Main factors likely to affect } \\
\text { vulnerability }\end{array}$ \\
\hline \multirow[t]{8}{*}{$\begin{array}{l}\text { Continuous } \\
\text { and irregular }\end{array}$} & \multirow[t]{8}{*}{ Stress } & \multirow[t]{3}{*}{ Avoidance } & Settlement & Delayed or no arrival & $\begin{array}{l}\text { Dependence on spawning } \\
\text { grounds, behavioural } \\
\text { repertoire }\end{array}$ \\
\hline & & & Spawning & $\begin{array}{l}\text { Number and timing of spawning } \\
\text { events }\end{array}$ & $\begin{array}{l}\text { Dependence on spawning } \\
\text { grounds, behavioural } \\
\text { repertoire }\end{array}$ \\
\hline & & & Parental care & Brood desertion & $\begin{array}{l}\text { Value of current vs. future } \\
\text { broods }\end{array}$ \\
\hline & & \multirow[t]{3}{*}{$\begin{array}{l}\text { Increased } \\
\text { cortisol }^{\mathrm{a}}\end{array}$} & Development & Timing of maturation & $\begin{array}{l}\text { Timing of exposure, potential } \\
\text { for postponement }\end{array}$ \\
\hline & & & & Maternal effects & $\begin{array}{l}\text { Species-specific maternal } \\
\text { buffers }\end{array}$ \\
\hline & & & Spawning & $\begin{array}{l}\text { Courtship, mate-choice, number } \\
\text { and quality of offspring }\end{array}$ & $\begin{array}{l}\text { Sensitivity, potential for } \\
\text { postponement }\end{array}$ \\
\hline & & \multirow[t]{2}{*}{$\begin{array}{l}\text { Condition- } \\
\operatorname{loss}^{\mathrm{a}}\end{array}$} & Settlement & Spawning migration & $\begin{array}{l}\text { Baseline condition during } \\
\text { migration }\end{array}$ \\
\hline & & & Spawning & $\begin{array}{l}\text { Number and timing of spawning } \\
\text { events }\end{array}$ & $\begin{array}{l}\text { Baseline condition during } \\
\text { spawning }\end{array}$ \\
\hline \multirow[t]{5}{*}{ Continuous } & \multirow{5}{*}{$\begin{array}{l}\text { Masking } \\
\text { and } \\
\text { Hearing- } \\
\text { loss }^{b}\end{array}$} & \multirow{4}{*}{$\begin{array}{l}\text { Loss of } \\
\text { cues and } \\
\text { signals }\end{array}$} & Development & Priming, ovulation & $\begin{array}{l}\text { Importance of acoustic cues for } \\
\text { development }\end{array}$ \\
\hline & & & Settlement & Localization of spawning grounds & $\begin{array}{l}\text { Importance of acoustic cues for } \\
\text { location }\end{array}$ \\
\hline & & & Spawning & $\begin{array}{l}\text { Mate-localization, courtship, mate- } \\
\text { choice, number and quality of } \\
\text { offspring }\end{array}$ & $\begin{array}{l}\text { Importance and flexibility of } \\
\text { acoustic signals }\end{array}$ \\
\hline & & & Parental care & Predator defence & $\begin{array}{l}\text { Importance of acoustic cues for } \\
\text { predator detection }\end{array}$ \\
\hline & & $\begin{array}{r}\text { Changes in } \\
\text { signalling }\end{array}$ & Spawning & $\begin{array}{l}\text { Courtship, mate-choice, quality of } \\
\text { offspring }\end{array}$ & $\begin{array}{l}\text { Importance and flexibility of } \\
\text { acoustic signals, costs of } \\
\text { signal changes }\end{array}$ \\
\hline
\end{tabular}

${ }^{\mathrm{a}}$ In the absence of avoidance

bote that the level of masking and hearing-loss will likely be affected by species-specific hearing abilities, as well as the loudness and frequency content of the masking sound

available for migration, which may also lead to a delayed arrival (Schreck et al. 2001). A delayed arrival at spawning grounds could incur costs, such as the loss of spawning opportunities or decreased offspring survival if a mismatch arises between the time of hatching and peaks in food availability (Houde 2008). In addition, avoidance behaviour after arrival could lead to movement away from the spawning ground. For example, during spawning, herring (Clupea harengus, Clupeidae), continuously choose between spawning in the water column and avoiding predation- risk by moving towards the bottom (Nøttestad et al. 1996, Skaret et al. 2003).

In general, the response of an animal to a stressor will depend on a trade-off between the cost of being stressed and the cost of avoiding the stressor (Beale 2007; Schreck et al. 2016). If the costs of avoidance are too high, animals may remain and spawn, but failure to avoid the stressor may lead to increased stress-levels and decreased reproductive success. Because anthropogenic stressors are comparatively new on an evolutionary time-scale, animals may not yet have had time to evolve appropriate response that 
would incur lesser costs, and its response could, therefore, be mal-adaptive. For example, many fish respond to stress with a freeze reaction, which would hamper the avoidance of noisy areas (Popper et al. 2003; Wright 2007). Thus, we can predict that the reproductive biology and the behavioural repertoire of a species will affect the likelihood of avoidance: Pelagic spawners may be more likely to avoid noise, while species that depend on specific spawning grounds may remain, even if noise exposure induces stress. In addition, the behavioural response to stress will affect the likelihood of avoidance.

\section{Effects of stress during spawning}

Effects of stress on reproduction can include effects on courtship, nest defence and mate choice (Schreck 2010). This may lead to a lower spawning volume, but also to a decreased quality of the offspring if suboptimal mates are chosen. In addition, cortisol can have a direct detrimental effect on offspring development. Hormonal responses to stress are generally attenuated in new-born animals, but some fishes can produce cortisol already before hatching (Barton 2002). Cortisol may also be passed on to the offspring if the mother was stressed during oogenesis (Kamler 2005), and negatively affect the offspring (Schreck et al. 2001; Nesan and Vijayan 2012). However, there is a clear advantage for females to protect their eggs, and maternal systems may therefore have evolved to buffer eggs from negative effects of stress (Schreck et al. 2001). Thus, while overall reproductive output is likely to be affected by stress, whether and how effects of stress are passed on to the offspring may be highly dependent on the species.

\section{Effects of stress on parental care}

Vertebrates from a great range of taxa have been shown to be less sensitive to stress during the breeding period than in the rest of the year (Wingfield and Sapolsky 2003). There is little specific literature on the effects of noise on fish parental care. In birds (western sandpipers, Calidris mauri, Scolopacidae), there is some evidence that the sex that provides parental care is less sensitive to increased stress levels than the other sex, suggesting that parental care reduces the physiological and behavioural response to a stressor (O'Reilly and Wingfield 2003). However, severe stress may lead to reactivation of the sensitivity to stress, which may lead to the desertion of current broods in favour of future reproduction (Astheimer et al. 1995). Brood desertion should only be expected if the cost-benefit ratio in the current brood is high compared to the potential for future reproduction (Trivers 1972; Clutton-Brock 1991). Thus, noiseinduced stress may be expected to have a reduced effect during periods of parental care, unless it exceeds a certain threshold.

Predicted effects of masking on reproduction

\section{Effects of masking on sexual development}

Courtship sounds may enhance egg development. In female Mozambique tilapias (Oreochromis mossambica, Cichlididae) male sounds induced priming for oviposition (Marshall 1972). Similarly, in female fringed darters (Etheostoma crossopterum, Percidae), male courtship sounds led to a decline in circulating oestrogen (Noel 2012), suggesting that conspecific sounds can induce ovulation (Kime 1993; Zeyl et al. 2016). These findings suggest that masking may hamper physiological processes that prepare females for ovulation in some species.

\section{Effects of masking on settlement on spawning grounds}

Vocal fish may use choruses to locate spawning grounds. Fish sounds vary in broadcasting range from only a few centimetres to hundreds of meters. Although most fish will likely communicate within a range of a few centimetres to meters (gobies (Gobiidae): Lugli and Fine 2003, toadfishes: Fine and Lenhardt 1983, Alves et al. 2016, damselfishes: Myrberg et al. 1986, Codarin et al. 2009, sweepers (Pempheridae): Radford et al. 2015), some fish calls range over a few hundred meters (e.g. Sciaenidae and Gadidae: Sprague and Luczkovich 2012; Codarin et al. 2009; Locascio and Mann 2011; Parsons et al. 2012; Stanley et al. 2017), and others form large choral spawning aggregations whereby male sounds are thought not only to serve as a long-range signal to attract females to the spawning arena but also to synchronize the reproductive behaviour of the spawning pair (Hawkins and Amorim 2000, Parsons et al. 2009, Casaretto et al. 2015). To date, there have been few studies assessing the decrease in communication 
active space by anthropogenic noise in fish but they point to a reduction of a few meters to several 100 meters in different species (Radford et al. 2015; Parsons et al. 2012; Stanley et al. 2017). However, because the source levels of most fish sounds are unknown, there is some uncertainty around these numbers. In addition, these studies have focussed on detection distance rather than the distance for comfortable communication. An example of how to gain information on the distance for comfortable communication is the approach adopted in Alves et al. (2016): the authors report the precision of the representation in the auditory pathway of calls recorded at different distances, it seems possible with this method to reliably tell at which distance receivers can extract information from biologically important sounds. Because a reduction in the active space for communication by masking could have major implications for reproduction for fish that rely on sound to locate and choose mates, providing more accurate estimates of the effect of noise on communication distances should be a research priority.

There is currently no evidence suggesting that nonvocal fish use acoustic cues to locate spawning grounds, however, the soundscape of an environment may well be important for migrating fish (Slabbekoorn and Bouton 2008; Fay 2009). In damselfish larvae, the disturbance of sound cues hampers orientation to appropriate settling sites (Holles et al. 2013). There is yet very little evidence of acoustic orientation in adult fish, but in the freshwater species avu (Plecoglossus altivelis) adults prefer playbacks of fish ladders over playback of river sound (Febrina et al. 2015). Furthermore, some fishes can register minor changes in sound patterns, which could mean that noise could potentially hamper spawning migration in non-vocal fish (Purser et al. 2016; Slabbekoorn et al. 2010).

\section{Effects of masking during spawning}

Many fish species rely on acoustic signalling during reproductive activities, including mate attraction, courtship and mate choice, as well as for spawning synchronisation (Myrberg and Lugli 2006). Calling behaviour may even be a prerequisite for spawning success, as was shown in a toadfish (Halobatrachus didactylus, Batrachoididae); Amorim et al. 2016). Acoustic courtship signals may also correlate with qualities of the sender, such as size and condition, and affect mating success (Reviewed in Amorim et al. 2015). Sexual selection can be sensitive to relative changes in how well signals propagate in different sensory modalities due to variation in environmental properties (Miller and Svensson 2014; Halfwerk and Slabbekoorn 2015). The disturbance of visual and chemical mating signals by turbidity (cichlids: Seehausen et al. 1997; three-spined sticklebacks (Gasterosteus aculeatus, Gasterosteidae): Candolin et al. 2015; sand gobies (Pomatoschistus minutus, Gobiidae): Jarvenpää and Lindstrom 2004) or endocrine disruptors (sand gobies: Lehtonen et al. 2009; Saaristo et al. 2009), for example, has been found to lead to a break-down in sexual selection in fish. The resulting effects of masking will depend on how important acoustic signals are for mate choice. Most vocal fish species also use other sensory channels and animals may switch to other modalities in response to masking (van der Sluijs et al. 2011). Such compensation may incur costs, which may not outweigh the benefits, and therefore render the animal vulnerable to the disturbance (Candolin and Wong 2012; Read et al. 2013; Candolin et al. 2015). Thus, a species' susceptibility to noise exposure may depend on the importance of the acoustic signals during reproductive interactions.

\section{Effects of masking on parental care}

Successful nest defence (and hence egg survival) and adult survival may be negatively affected by masking of acoustic predator cues (Schreck 2010). The strength of such an effect will depend on the importance of acoustic cues compared to other (e.g. visual) cues in the environment.

\section{Predicted effects of hearing-loss on reproduction}

The effects of hearing-loss on reproduction will be similar to effects of masking on reproduction, except that effects will be more prolonged and could, therefore, impair reproduction long after a period of exposure to a sound. This may be especially important when juveniles are exposed to sounds that cause permanent hearing-loss. For example, fish raised in aquaria have been found to have higher hearingthresholds than wild-caught fish (Caiger et al. 2012). Thus, early exposure to noise may affect hearing in adults (Table 4). 


\section{Qualitative test of predictions}

To assess whether current literature on the effects of anthropogenic noise on stress fits our predictions (Table 4), we used papers that directly tested an effect of sound exposure on a measure of reproductive success. These papers were excluded from the metaanalyses. We found four papers that directly explored the effects of increased sound levels on a measure of reproductive success (Sierra-Flores et al. 2015; Nedelec et al. 2017; de Jong et al. 2018a; Blom et al. 2019), while five other studies investigated behavioural responses related to reproduction without providing direct data on reproductive success (Bruintjes and Radford 2013; Picciulin et al. 2010, 2012; Holt and Johnston 2014; la Manna et al. 2016; de Jong et al. 2018b). These were used for a first qualitative test of our predictions. Future studies will be needed to provide a more rigorous test. We are not aware of any published reports on tests of effects of noise on sexual development or the settlement of adult fish on spawning grounds, it is therefore currently not possible to test our predictions for these stages.

\section{Effects of noise during spawning}

Sierra-Flores et al. (2015) described spawning success in a group of Atlantic cod exposed to six hours of lowfrequency sound sweeps randomly distributed over the day for three months and compared it to a control group. In this study, the noise-exposed group produced fewer viable eggs, with lower fertilization rates and higher levels of the stress-hormone cortisol in eggs. In addition, despite similar total amount of eggs produced per female in both populations, the spawning period was shorter in the noise-exposed population. However, because the treatment was not replicated, the authors were unable to test whether this difference was caused by the noise treatment itself. Recent research found that spawning success can be affected by continuous noise in the painted goby (de Jong et al. 2018a); females were less likely to spawn with an available male under continuous noise. Such reduction in spawning success may be related to the disturbance of communication in vocal species or to altered behaviour due to stress. Several studies have shown that noise can affect acoustic signalling in fish and their spawning behaviour. For instance, Holt and Johnston (2014) reported that courtship growls were louder in the blacktail shiner (Cyprinella venusta, Cyprinidae) during elevated ambient noise levels, and suggested that it may become energetically costly to vocalise under noisy background conditions. Picciulin et al. (2012) reported that males of the brown meagre vocalise more during the quiet intervals following the repeated passages of a small boat, though this effect was not seen after a single exposure (Picciulin et al. 2012; La Manna et al. 2016). Thus, fish may compensate for communication loss by waiting for relatively quiet periods, in accordance to our predictions. In the previously mentioned study by de Jong et al. (2018a), two closely related species of gobies were less vocal when exposed to continuous noise for several days. In addition, females of the painted goby payed more attention to visual signals in addition to acoustic signals in a noisy environment (de Jong et al. 2018b). Blom et al. (2019) found that spawning success in common gobies was significantly affected by continuous sound, but not by intermittent sound. Thus, as predicted, continuous noise may affect communication more severely than intermittent noise. Painted goby males also reduced visual courtship behaviour (de Jong et al. 2018b), highlighting that noise can affect courtship in more than one modality (see also Kunc et al. 2014; Halfwerk and Slabbekoorn 2015). Thus, spawning success may be sensitive to noise disturbance not only in vocal species.

\section{Effects of noise on parental care}

Nedelec et al. (2017) found in a field experiment that breeding pairs of the spiny chromis (Acanthochromis polyacanthus, Pomacentridae) exposed to playbacks of motorboat noise close to the nest suffered complete brood mortality more often than pairs exposed to playback of ambient sound, likely due to decreased interactions with offspring and increased predation risk. Bruintjes and Radford (2013) found that noise exposure reduced nest repair (digging behaviour), which is vital to maintain hiding and breeding shelters for groups of cooperatively breeding cichlids (Neolamprologus pulcher, Cichlididae). A decreased defence against predators of eggs and fry was also reported in their study, but only when there were no eggs in the nest. Subordinates suffered more aggression, but did not change the frequency of submissive behaviours. The increase of agonistic acts during nest defence was also found in the previously described 
field experiment (Nedelec et al. 2017). Picciulin et al. (2010) found a decrease in time spent caring for and defending of the nest in a damselfish and in a goby, respectively. This suggests that noise can redirect behaviour away from reproductive investments, as well as rendering such behaviours less effective. Several studies have tested effects of noise on egg and larval survival in the absence of parents (e.g. Banner and Hyatt 1973; Bolle et al. 2012; Bruintjes and Radford 2014, Nedelec et al. 2015), but because they are not related to effects on parental effort, we did not discuss these in this review.

\section{Knowledge gaps}

Currently, most of the guidelines for anthropogenic noise are focussed on reducing overall sound levels (Popper et al. 2014; Popper and Hawkins 2019). However, one of the main issues we encountered during this review was that it is next to impossible to compare sound levels between studies, because sounds are described in very different ways, and the terminology varies among studies. We advise authors to stick to the international standard for terminology in underwater acoustics (ISO 18405:2017), and report SPL, SEL and peak sound level both before and during exposure, as well as the distribution of the energy over the frequency spectrum, preferably for both pressure and particle motion. Recordings of the actual sound levels in the treatments should also be provided if possible.

We are not aware of any studies addressing effects of anthropogenic noise on spawning migration or spawning site-choice, nor on gonadal development or choice of reproductive strategy. It will be vital to study this in both vocal and non-vocal fish to assess whether noise mainly affects fish that use sound communication, or whether noise could potentially affect all fish. Alternatively, noise could lead to distraction (reviewed in Dukas 2004; Chan and Blumstein 2011), which may be especially important during parental care, because the offspring of distracted parents may have a lower likelihood to survive predation (Nedelec et al. 2017). Courtship signals, on the other hand, evolved to attract and sustain receiver attention in the face of distraction by competitors (Dukas 2004; Hebets 2005; Hughes et al. 2012). Therefore, we expect that noise-exposure would have to be extreme to distract fish from courtship.

Effects of stress and distraction can also lead to changes in other signalling modalities such as visual or chemical signals (Kunc et al. 2014; Halfwerk and Slabbekoorn 2015). In addition, masking of acoustic signals could lead to changes in signalling behaviour if animals try to compensate for a loss of signalling efficacy in one modality by increasing efforts in another modality (Bro-Jørgensen 2010). A first test has shown that males of two species of gobies reduce calling effort, but do not increase visual signalling effort under noisy circumstances (de Jong et al. 2018b). Further effort should be dedicated to determine whether other species can compensate for a loss of signal efficacy in the acoustic modality by shifting signalling efforts to the visual or the chemical modality.

Responses to stressors may vary between individuals or contexts. Coping styles (Koolhaas et al. 1999; Øverli et al. 2007; Conrad et al. 2011), body size (Engås et al. 1996; Kastelein et al. 2017), condition (Purser et al. 2016), and group composition (Magnhagen et al. 2017). Fish, e.g. herring, have been shown to react differently to ship noise depending on whether they are in an overwintering state (Vabø et al. 2002) or a pre-spawning state (Skaret et al. 2005). In addition, anthropogenic disturbances generally involve more than one sound type, such as seismic surveys that involve ship as well as air guns, and these sounds may interact to cause responses in fish. Furthermore, stress from noise may or may not interact with other stressors such as light (Shafiei Sabet et al. 2016), and spawning habitats may be affected by other stressors at the same time, such as increasing temperatures, rendering it crucial to study noise in a multi-stressor context.

To answer such these questions, the use of a valid control is needed to establish causality in responses to treatment. The controls used in published studies vary widely, from none at all, to the playback of different sounds (Suppl. Table 2). What type of control is valid will depend on the question asked and the type of study, but controls should be considered carefully in the design of future studies (Slabbekoorn 2016). 


\section{Conclusions}

Overall, our meta-analyses suggest that irregular continuous sound (e.g. heavy ship traffic) may have the most pronounced effect on stress, masking and hearing-loss, which indicates that it may also have the most pronounced effect on fish reproduction. While current mitigation programs mostly focused on reducing average sound levels, our review suggests that it may also be important to increase predictability and decrease continuity of noise. Such findings are important for the development of technology and management. For management, this could mean that a ban on vessels in certain periods or areas, could be more effective than just an overall decrease in average noise levels. In technology, e-seismic and marine vibrators are being developed to reduced source level during seismic exploration, but these operate continuously rather than intermittently (e.g. Dellinger et al. 2016; Hegna et al. 2018). A closer link between research and technology would hence be valuable to ensuring that development focus on reducing those sound components that have proven most harmful to fish and other marine animals.

From our review, we predict that noise-induced stress will affect mainly those species that do not have the potential to relocate or delay spawning, for example, those species that are bound to specific spawning grounds and have a restricted spawning period. In contrast to the spawning period, most species seem to be relatively resilient to stress during egg development and parental care, even though the latter will often restrict a species potential to relocate. Masking and hearing-loss will mainly affect species for which sound is crucial to reproduction, such as species that use sound to locate spawning grounds and those that use acoustic communication during spawning. In the latter case, the severity of the impact may depend on the flexibility of the species' signalling repertoire. Parental care may also be affected if masking (or distraction) hampers the timely detection of predators.

Here, our aim was to develop predictions on what types of noise would most likely affect fish reproduction at different stages, and across species. To fulfil this goal, it was unavoidable to generalise findings and lump studies. Therefore, we must remain cautious in assuming that any of the species or stages that have not been identified as particularly sensitive by this review will be unaffected by noise, until experimental tests have confirmed their resilience. While our metaanalyses helped build a better understanding of the effects of noise on fish reproduction, it is now important to focus research efforts towards the development of an experimental framework dedicated to testing these predictions on fish impact during reproduction. This framework will benefit from a combination of sound-exposure experiments in controlledsettings (tanks, mesocosms) and in situ studies on freeranging animals exposed to real-life sound sources directly in their natural environments (c.f. Slabbekoorn 2016), as well as a multi-stressor approach.

Acknowledgements Open Access funding provided by Institute Of Marine Research. We thank Henning Wehde and Daniel Nyqvist for comments on a previous version of this manuscript. KdJ, TNF, GR and LDS were funded by Equinor and the Institute of Marine Research. MCPA was funded by the Science and Technology Foundation, Portugal (Strategic Project UID/MAR/04292/2013 Granted to MARE and Project PTDC/ BIA-BMA/29662/2017).

\section{Compliance with ethical standards}

Conflict of interest The authors declare that they have no conflict of interest.

Open Access This article is licensed under a Creative Commons Attribution 4.0 International License, which permits use, sharing, adaptation, distribution and reproduction in any medium or format, as long as you give appropriate credit to the original author(s) and the source, provide a link to the Creative Commons licence, and indicate if changes were made. The images or other third party material in this article are included in the article's Creative Commons licence, unless indicated otherwise in a credit line to the material. If material is not included in the article's Creative Commons licence and your intended use is not permitted by statutory regulation or exceeds the permitted use, you will need to obtain permission directly from the copyright holder. To view a copy of this licence, visit http://creativecommons.org/licenses/by/4.0/.

\section{References}

Akaike H (1973) Information theory as an extension of the maximum likelihood principle. In: Petrov B, Csaki F (eds) Second international symposium on information theory. Akademiai Kiado, Budapest, pp 267-281

Alves D, Amorim MCP, Fonseca PJ (2016) Assessing acoustic communication active space in the Lusitanian toadfish. J Exp Biol 219:1122-1129

Amorim MCP (2006) Diversity of sound production in fish. In: Ladich F, Collin S, Moller P et al (eds) Communication in fishes. Science Publishers, Enfield, pp 71-104 
Amorim MCP, Pedroso SS, Bolgan M et al (2013) Painted gobies sing their quality out loud: acoustic rather than visual signals advertise male quality and contribute to mating success. Funct Ecol 27:289-298

Amorim MCP, Vasconcelos RO, Fonseca PJ (2015) Fish sounds and mate choice. Sound communication in fishes. Springer, Berlin, pp 1-33

Amorim MCP, Conti C, Sousa-Santos C et al (2016) Reproductive success in the Lusitanian toadfish: influence of calling activity, male quality and experimental design. Physiol Behav 155:17-24

Amorim MCP, Vasconcelos RO, Bolgan M, Pedroso SS, Fonseca PJ (2018) Acoustic communication in marine shallow waters: testing the acoustic adaptive hypothesis in sand gobies. J Exp Biol. https://doi.org/10.1242/jeb.183681

Amoser S, Ladich F (2003) Diversity in noise-induced temporary hearing loss in Otophysine fishes. J Acoust Soc Am 113:2170-2179

Andrew RK, Howe BM, Mercer JA et al (2002) Ocean ambient sound: comparing the 1960 s with the 1990 s for a receiver off the California coast. Acoust Res Let Online 3:65-70

Astheimer LB, Buttemer WA, Wingfield JC (1995) Seasonal and acute changes in adrenocortical responsiveness in an arctic-breeding bird. Horm Behav 29:442-457

Banner A, Hyatt M (1973) Effects of noise on eggs and larvae of two estuarine fishes. Trans Am Fish Soc 102:134-136

Barton BA (2002) Stress in fishes: a diversity of responses with particular reference to changes in circulating corticosteroids. Integr Comp Biol 42:517-525

Bates D, Mächler M, Bolker B et al (2015) Fitting linear mixedeffects models using lme4. J Stat Softw. https://doi.org/10. 18637/jss.v067.i01

Beale CM (2007) The behavioral ecology of disturbance responses. Int J Comp Psychol 20:111-120

Belanger AJ, Bobeica I, Higgs DM (2010) The effect of stimulus type and background noise on hearing abilities of the round goby Neogobius melanostomus. J Fish Biol 77:1488-1504

Blom E-L, Kvarnemo C, Dekhla I, Schöld S, Andersson MH, Svensson O, Amorim MCP (2019) Continuous but not intermittent noise has a negative impact on mating success in a marine fish with paternal care. Sci Rep 9:5494. https:// doi.org/10.1038/s41598-019-41786-X

Bolle LJ, de Jong CAF, Bierman SM et al (2012) Common sole larvae survive high levels of pile-driving sound in controlled exposure experiments. PLoS ONE 7:e33052

Boonstra R, Hik D, Singleton GR et al (1998) The impact of predator-induced stress on the snowshoe hare cycle. Ecol Monogr 68:371-394

Bradbury JW, Vehrencamp SL (2011) Principles of animal communication, 2nd edn. Sinauer Associates, Sunderland (MA)

Brenowitz EA (1982) The active space of red-winged blackbird song. J Comp Physiol 147(4):511-522

Bretschneider F, van den Berg AV, van Veen H et al (2013) Zebrafish can hear sound pressure and particle motion in a synthesized sound field. Anim Biol 63:199-215

Bro-Jørgensen J (2010) Dynamics of multiple signalling systems: animal communication in a world in flux. Trends Ecol Evol 25(5):292-300

Bruintjes R, Radford AN (2013) Context-dependent impacts of anthropogenic noise on individual and social behaviour in a cooperatively breeding fish. Anim Behav 85:1343-1349
Bruintjes R, Radford AN (2014) Chronic playback of boat noise does not impact hatching success or post-hatching larval growth and survival in a cichlid fish. PeerJ 2:e594

Brumm H, Slabbekoorn H (2005) Acoustic communication in noise. In: Slater PJB, Snowdon CT, Roper TJ, Brockmann HJ, Naguib M (eds) Advances in the study of behavior. Academic Press, San Diego, pp 151-209

Caiger PE, Montgomery JC, Radford CA (2012) Chronic lowintensity noise exposure affects the hearing thresholds of juvenile snapper. Mar Ecol Prog Ser 466:225-232

Candolin U, Wong BBM (2012) Sexual selection in changing environments: consequences for individuals and populations. In: Candolin U, Wong BBM (eds) Behavioural responses to a changing world: mechanisms and consequences. Oxford University Press, Oxford, pp 201-215

Candolin U, Tukiainen I, Bertell E (2015) Environmental change disrupts communication and sexual selection in a stickleback population. Ecology. https://doi.org/10.1890/ 15-1090.1

Carroll AG, Przeslawski R, Duncan A et al (2017) A critical review of the potential impacts of marine seismic surveys on fish \& invertebrates. Mar Pollut Bull 114:9-24

Casaretto L, Picciulin M, Hawkins AD (2015) Mating behaviour by the haddock (Melanogrammus aeglefinus). Environ Biol Fish 98:913-923

Chan AAY, Blumstein DT (2011) Attention, noise, and implications for wildlife conservation and management. Appl Anim Behav Sci 131:1-7

Chan AAY, Giraldo-Perez P, Smith S et al (2010) Anthropogenic noise affects risk assessment and attention: the distracted prey hypothesis. Biol Lett 6:458-461

Chapman CJ, Hawkins AD (1973) A field study of hearing in the cod, Gadus morhua L. J Comp Physiol 85:147-167

Clark CW, Ellison WT, Hatch BL et al (2009) Acoustic masking in marine ecosystems: intuitions, analysis, and implication. Mar Ecol Prog Ser 395:201-222

Clutton-Brock TH (1991) The evolution of parental care. Princeton University Press, Princeton

Codarin A, Wysocki LE, Ladich F et al (2009) Effects of ambient and boat noise on hearing and communication in three fish species living in a marine protected area (Miramare, Italy). Mar Pollut Bull 58:1880-1887

Colin PL, Sadovy YJ, Domeier ML (2003) Manual for the study and conservation of reef fish aggregations. Society for the Conservation of Reef Fish Aggregations, Fallbrook

Conrad JL, Weinersmith KL, Brodin T, Saltz JB, Sih A (2011) Behavioural syndromes in fishes: a review with implications for ecology and fisheries management. J Fish Biol 78:395-435. https://doi.org/10.1111/j.1095-8649.2010. 02874.x

Corwin JT, Oberholtzer JC (1997) Fish n' chicks: model recipes for hair-cell regeneration? Neuron 19:951-954

Cox K, Brennan LP, Gerwing TG et al (2018) Sound the alarm: a meta-analysis on the effect of aquatic noise on fish behavior and physiology. Glob Change Biol 24:3105-3116

Crawford JD, Jacob P, Benech V (1997) Sound production and reproductive ecology of strongly acoustic fish in Africa: Pollimyrus isidori, Mormyridae. Behaviour 134:677-725

de Jong K, Bouton N, Slabbekoorn H (2007) Azorean rock-pool blennies produce size-dependent calls in a courtship context. Anim Behav 74:1285-1292 
de Jong K, Amorim MCP, Fonseca PJ et al (2018a) Noise can affect acoustic communication and subsequent spawning success in fish. Environ Pollut 237:814-823

de Jong K, Amorim MCP, Fonseca PJ et al (2018b) Noise affects multimodal communication during courtship in a marine fish. Front Ecol Evol 6:113

de Soto NA, Kight C (2016) Physiological effects of noise on aquatic animals. In: Solan M, Whiteley N (eds) Stressors in the marine environment: physiological and ecological responses, societal implications. Oxford University Press, Oxford, pp 135-158

Deak T (2007) From classic aspects of the stress response to neuroinflammation and sickness: implications for individuals and offspring. Int J Comp Psychol 20:96-110

Dellinger J, Ross A, Meaux D, Brenders A, Gesoff G, Etgen J, Naranjo J, Openshaw G, Harper M (2016) Wolfspar ${ }^{\circledR}$, an "FWI-friendly" ultralow-frequency marine seismic source. SEG expanded abstracts, pp 4891-4895

Dooling RJ, Lohr B, Dent ML (2000) Hearing in birds and reptiles. In: Dooling RJ, Fay RR, Popper AN (eds) Comparative hearing: birds and reptiles. Springer, New York, pp 308-359

Dooling RJ, Leek MR, Popper AN (2015) Effects of noise on fishes: what we can learn from humans and birds. Integr Zool 10:29-37

Dukas R (2004) Causes and consequences of limited attention. Brain Behav Evol 63:197-210

Engås A, Løkkeborg S, Ona E, Vold A (1996) Effects of seismic shooting on local abundance and catch rates of cod (Gadus morhua) and haddock (Melanogrammus aeglefinus). Can J Fish Aquat Sci 53:2238-2249. https://doi.org/10.1139/f96177

Enger PS (1967) Hearing in herring. Comp Biochem Physiol 22:527-538

Erbe C, Reichmuth C, Cunningham K et al (2016) Communication masking in marine mammals: a review and research strategy. Mar Pollut Bull 103:15-38

Farcas A, Thompson PM, Merchant ND (2016) Underwater noise modelling for environmental impact assessment. Environ Impact Assess Rev 57:114-122

Fay RR (2009) Soundscapes and the sense of hearing of fishes. Integr Zool 4:26-32

Febrina R, Sekine M, Noguchi H, Yamamoto K, Kanno A, Higuchi $\mathrm{T}$ et al (2015) Modeling the preference of ayu (Plecoglossus altivelis) for underwater sounds to determine the migration path in a river. Ecol Model 299:102-113. https://doi.org/10.1016/j.ecolmodel.2014.12.010

Fine ML, Lenhardt ML (1983) Shallow-water propagation of the toadfish mating call. Comp Biochem Physiol A 76:225-231

Fine ML, Parmentier E (2015) Mechanisms of fish sound production. In: Ladich F (ed) Sound communication in fishes, animal signals and communication 4. Springer, Berlin, pp 77-126. https://doi.org/10.1007/978-3-7091-1846-7_3

Francis CD, Barber JR (2013) A framework for understanding noise impacts on wildlife: an urgent conservation priority. Front Ecol Environ 11:305-313

Frisk GV (2012) Noiseonomics: the relationship between ambient noise levels in the sea and global economic trends. Sci Rep 2:437. https://doi.org/10.1038/srep00437
Galhardo L, Oliveira RF (2009) Psychological stress and welfare in fish. ARBS Ann Rev Biomed Sci 11:1-20

Galhardo L, Vital J, Oliveira RF (2011) The role of predictability in the stress response of a cichlid fish. Physiol Behav 102:367-372

Gisiner RC (2016) Sound and marine seismic surveys. Acoust Today 12:10-18

Gutscher M, Wysocki LE, Ladich F (2011) Effects of aquarium and pond noise on hearing sensitivity in an Otophysine fish. Bioacoustics 20:117-136

Halfwerk W, Slabbekoorn H (2015) Pollution going multimodal. Biol Lett 11:20141051. https://doi.org/10.1098/ rsbl.2014.1051

Haviland-Howell G, Frankel AS, Powell CM et al (2007) Recreational boating traffic: a chronic source of anthropogenic noise in the Wilmington, North Carolina Intracoastal Waterway. J Acoust Soc Am 122:151-160

Hawkins AD, Amorim MCP (2000) Spawning sounds of the male haddock, Melanogrammus aeglefinus. Environ Biol Fish 59:29-41

Hawkins AD, Popper AN (2017) A sound approach to assessing the impact of underwater noise on marine fishes and invertebrates. ICES J Mar Sci 74:635-651

Hazelwood RA, Macey PC (2016) Modeling water motion near seismic waves propagating across a graded seabed, as generated by man-made impacts. J Mar Sci Eng 4:47

Hebets EA (2005) Attention-altering signal interactions in the multimodal courtship display of the wolf spider Schizocosa uetzi. Behav Ecol 16:75-82. https://doi.org/10.1093/ beheco/arh133

Hegna S, Klüver T, Lima J (2018) Benefits of continuous source and receiver side wavefields. SEG technical program expanded abstracts. Society of exploration geophysicists, pp 4-45

Higgs DM, Radford CA (2012) The contribution of the lateral line to 'hearing' in fish. J Exp Biol 216:1484-1490

Hildebrand JA (2009) Anthropogenic and natural sources of ambient noise in the ocean. Mar Ecol Prog Ser 395:5-20

Holles S, Simpson SD, Radford AN et al (2013) Boat noise disrupts orientation behaviour in a coral reef fish. Mar Ecol 485:295-300

Holst JC (2004) The herring. In: Skjoldal H (ed) The Norwegian Sea ecosystem. Fogbokforlaget, Norway

Holt DE, Johnston CE (2014) Evidence of the Lombard effect in fishes. Behav Ecol 25:819-826

Holt DE, Johnston CE (2015) Traffic noise masks acoustic signals of freshwater stream fish. Biol Conserv 187:27-33

Houde ED (2008) Emerging from Hjort's shadow. J N Atl Fish Sci 41:53-70

Hughes NK, Kelley JL, Banks PB (2012) Dangerous liaisons: the predation risks of receiving social signals. Ecol Lett 15:1326-1339. https://doi.org/10.1111/j.1461-0248.2012. 01856.x

Hurvich CM, Tsai C-L (1991) Bias of the corrected AIC criterion for underfitted regression and time series models. Biometrika 78:499-509

Jarvenpää M, Lindstrom K (2004) Water turbidity by algal blooms causes mating system breakdown in a shallowwater fish, the sand goby Pomatoschistus minutus. Proc R Soc Lond B Biol Sci 271:2361-2365 
Kamler E (2005) Parent-egg-progeny relationships in teleost fishes: an energetics perspective. Rev Fish Biol Fish 15:399

Kastelein RA, Jennings N, Kommeren A, Helder-Hoek L, Schop J (2017) Acoustic dose-behavioral response relationship in sea bass (Dicentrarchus labrax) exposed to playbacks of pile driving sounds. Mar Environ Res 130:315-324

Kime DE (1993) Classical and non-classical reproductive steroids in fish. Rev Fish Biol Fish 3:160-180

Koolhaas JM, Korte SM, Boer SF, Van Der Vegt BJ, Van Renen CG, Hopster H, De Jong IC, Ruis MAW, Blokhuis HJ (1999) Coping styles in animals: current status in behavior and stress-physiology. Neurosci Biobehav Rev 23:925-935

Kunc HP, Lyons GN, Sigwart JD et al (2014) Anthropogenic noise affects behavior across sensory modalities. Am Nat 184:E93-E100

Kunc HP, McLaughlin KE, Schmidt R (2016) Aquatic noise pollution: implications for individuals, populations, and ecosystems. Proc B 283:20160839

La Manna G, Manghi M, Perretti F et al (2016) Behavioral response of brown meagre (Sciaena umbra) to boat noise. Mar Pollut Bull 110:324-334

Ladich F (2013) Effects of noise on sound detection and acoustic communication in fishes. In: Brumm H (ed) Animal communication and noise. Springer, Berlin, pp 65-90

Lehtonen KK, Björk H, Lindström K (2009) Disruption of sexual selection in sand gobies (Pomatoschistus minutus) by $17 \alpha$-ethinyl stradiol, an endocrine disruptor. Horm Behav 55:530-537

Liu M, Wei QW, Du H, Fu ZY, Chen QC (2013) Ship noiseinduced temporary hearing threshold shift in the Chinese sucker (Bleeker, 1864) . J Appl Ichthyol 29(6):1416-1422

Locascio JV, Mann DA (2011) Localization and source level estimates of black drum (Pogonias cromis) calls. J Acoust Soc Am 130:1868-1879

Lugli M (2010) Sounds of shallow water fishes pitch within the quiet window of the habitat ambient noise. J Comp Physiol A Neuroethol Sens Neural Behav Physiol 196:439-451. https://doi.org/10.1007/s00359-010-0528-2

Lugli M, Fine ML (2003) Acoustic communication in two freshwater gobies: ambient noise and short-range propagation in shallow streams. J Acoust Soc Am 114:512-521

Madsen PT, Wahlberg M, Tougaard J, Lucke K, Tyack P (2006) Wind turbine underwater noise and marine mammals: implications of current knowledge and data needs. J Mar Ecol Prog Ser 309:279-295

Magnhagen C, Johansson K, Sigray P (2017) Effects of motorboat noise on foraging behaviour in Eurasian perch and roach: a field experiment. Mar Ecol Progr Ser 564:115-125. https://doi.org/10.3354/meps11997

Marley SA, Erbe C, Salgado-Kent CP (2016) Underwater sound in an urban estuarine river: sound sources, soundscape contribution, and temporal variability. Acoust Aust 44:171-186

Marshall JA (1972) Influence of male sound production on oviposition in female Tilapia mossambica (Pisces: Cichlidae). Am Zool 12:633-664

Mazerolle MJ (2017) AICcmodavg: model selection and multimodel inference based on (Q)AIC (c). R package version 2.1-1
McCauley R, Fewtrell J, Popper AN (2003) High intensity anthropogenic sound damages fish ears. J Acoust Soc Am 113:638-642

McDonald MA et al (2006) Increases in deep ocean ambient noise in the Northeast Pacific west of San Nicolas Island, California. J Acoust Soc Am 120:711-718

McKenna MF, Ross D, Wiggins SM, Hildebrand JA (2012) Underwater radiated noise from modern commercial ships. J Acoust Soc Am 131:92-103

Miller CW, Svensson EI (2014) Sexual selection in complex environments. Annu Rev Entomol 59:427-445

Monroe JD, Rajadinakaran G, Smith ME (2015) Sensory hair cell death and regeneration in fishes. Front Cell Neurosci 9:131. https://doi.org/10.3389/fncel.2015.00131

Morris SB, DeShon RP (2002) Combining effect size estimates in meta-analysis with repeated measures and independentgroups designs. Psychol Methods 7:105-125

Myrberg AA, Lugli M (2006) Reproductive behaviour and acoustical interactions. In: Ladich F (ed) Communication in fishes. Science Publishers, Enfield, pp 149-176

Myrberg AA, Mohler M, Catala JD (1986) Sound production by males of a coral reef fish (Pomacentrus partitus): its significance to females. Anim Behav 34:913-923

Narins PM, Wilson M, Mann DA (2013) Ultrasound detection in fishes and frogs: discovery and mechanisms. In: Köppl C, Manley G, Popper A, Fay R (eds) Insights from comparative hearing research. Springer handbook of auditory research, vol 49. Springer, New York, pp 133-156

Nedelec SJ, Simpson SD, Morley EL et al (2015) Impacts of regular and random noise on the behaviour, growth and development of larval Atlantic cod (Gadus morhua). Proc B 282:20151943

Nedelec SL, Campbell J, Radford AN et al (2016) Particle motion: the missing link in underwater acoustic ecology. Methods Ecol Evol 7:836-842

Nedelec SJ, Radford AN, Pearl L et al (2017) Motorboat noise impacts parental behaviour and offspring survival in a reef fish. Proc B 284:20170143

Nesan D, Vijayan MM (2012) Embryo exposure to elevated cortisol level leads to cardiac performance dysfunction in zebrafish. Mol Cell Endocrinol 363:85-91

New LF, Clark JS, Costa DP et al (2014) Using short-term measures of behaviour to estimate long-term fitness of southern elephant seals. Mar Ecol Progr Ser 496:99-108

Noel PS (2012) Acoustic communication, reproduction and hormone modulation in the Catonotus darters

Nøttestad L, Aksland M, Beltestad A et al (1996) Schooling dynamics of Norwegian spring spawning herring (Clupea harengus L.) in a coastal spawning area. Sarsia 80:277-284

Ogden GL, Zurk LM, Jones ME et al (2011) Extraction of small boat harmonic signatures from passive sonar. J Acoust Soc Am 129:3768

O'Reilly KM, Wingfield JC (2003) Seasonal, age, and sex differences in weight, fat reserves, and plasma corticosterone in western sandpipers. The Condor 105:13-26

Øverli Ø, Sørensen C, Pulman KGT, Pottinger TG, Korzan W, Summers CH, Nilsson GE (2007) Evolutionary background for stress-coping styles: relationships between physiological, behavioral, and cognitive traits in nonmammalian vertebrates. Neurosci Biobehav Rev 
31:396-412. https://doi.org/10.1016/j.neubiorev.2006.10. 006

Parsons MJG, McCauley RD, Duncan AJ (2009) Localisation of an individual mulloway (Argyrosomus japonicus) within a spawning aggregation and their behavioural characteristics throughout a diel spawning period. ICES J Mar Sci 66:1007-1014

Parsons MJG, McCauley RD, Mackie MC et al (2012) In situsource levels of mulloway (Argyrosomus japonicus) calls. J Acoust Soc Am 132:3559-3568

Parvulescu A (1967) The acoustics of small tanks. Mar Bio Acoust 2:7-13

Picciulin M, Sebastianutto L, Codarin A et al (2010) In situ behavioural responses to boat noise exposure of Gobius cruentatus (Gmelin, 1789; fam. Gobiidae) and Chromis chromis (Linnaeus, 1758; fam. Pomacentridae) living in a Marine Protected Area. J Exp Mar Biol Ecol 386:125-132

Picciulin M, Sebastianutto L, Codarin A et al (2012) Brown meagre vocalization rate increases during repetitive boat noise exposures: a possible case of vocal compensation. J Acoust Soc Am 132:3118-3124

Pollack I (1975) Auditory informational masking. J Acoust Soc Am 57:S5

Popper AN, Fay RR (2011) Rethinking sound detection by fishes. Hear Res 273:25-36

Popper AN, Hawkins AD (2018) The importance of particle motion to fishes and invertebrates. J Acoust Soc Am 143:470-488

Popper AN, Hawkins AD (2019) An overview of fish bioacoustics and the impacts of anthropogenic sounds on fishes. J Fish Biol. https://doi.org/10.1111/jfb.13948

Popper AN, Fay RR, Platt C et al (2003) Sound detection mechanisms and capabilities of teleost fishes. In: Collin S, Marshall N (eds) Sensory processing in aquatic environments. Springer, New York, pp 3-38

Popper AN, Hawkins AD, Fay RR et al (2014) ASA S3/SC1.4 TR-2014 sound exposure guidelines for fishes and sea turtles: a technical report prepared by ANSI-accredited standards committee S3/SC1 and registered with ANSI. Springer, Berlin

Pörtner HO, Farrel AP (2008) Physiology and climate change. Science 322:690-692

Purser J, Bruintjes R, Simpson SD et al (2016) Condition-dependent physiological and behavioural responses to anthropogenic noise. Physiol Behav 155:157-161

Radford AN, Kerridge E, Simpson SD (2014) Acoustic communication in a noisy world: can fish compete with anthropogenic noise? Behav Ecol 25:1022-1030

Radford CA, Ghazali SJAG, Montgomery JC (2015) Vocalisations of the bigeye Pempheris adspersa: characteristics, source level and active space. Aust J Exp Biol Med Sci 218:940-948

Radford AN, Lèbre L, Lecaillon G, Nedelec SL, Simpson SD (2016) Repeated exposure reduces the response to impulsive noise in European seabass. Glob Change Biol 22(10):3349-3360

Read J, Jones G, Radford AN (2013) Fitness costs as well as benefits are important when considering responses to anthropogenic noise. Behav Ecol 25:4-7

Romero ML, Butler LK (2007) Endocrinology of stress. Int J Comp Psychol 20:89-95
Romine JG, Jensen NR, Parsley MJ, Gaugush RF, Severson TJ, Hatton TW, Adams RF, Gaikowski MP (2015) Response of bighead carp and silver carp to repeated water gun operation in an enclosed shallow pond. N Am J Fish Manag 35:440-453. https://doi.org/10.1080/02755947.2015. 1012279

Rose GA, Bradbury IR, de Young B (2008) Rebuilding Atlantic cod: lessons from a spawning ground in coastal Newfoundland. In: Kruse GH, Drinkwater K, Ianelli JN, Link JS, Stram DL, Wespestad V, Woodby D (eds) Resiliency of gadid stocks to fishing and climate change. Alaska Sea Grant College Program, Fairbanks, pp 197-218

Rossington K, Benson T, Lepper P et al (2013) Eco-hydroacoustic modeling and its use as an EIA tool. Mar Pollut Bull 75:235-243

Rowe S, Hutchings JA (2006) Sound production by Atlantic cod during spawning. Trans Am Fish Soc 135:529-538

Saaristo M, Craft JA, Lehtonen KK et al (2009) Sand goby (Pomatoschistus minutus) males exposed to an endocrine disrupting chemical fail in nest and mate competition. Horm Behav 56:315-321

Sapolsky RM, Romero LM, Munck AU (2000) How do glucocorticoids influence stress responses? Integrating permissive, suppressive, stimulatory, and preparative actions. Endocr Rev 21:55-89

Scholik A, Yan H (2001) Effects of underwater noise on auditory sensitivity of a cyprinid fish. Hear Res 152:17-24

Scholik AR, Yan HY (2002) The effects of noise on the auditory sensitivity of the bluegill sunfish, Lepomis macrochirus. Comp Biochem Physiol A Mol Integr Physiol 133(1):43-52

Schreck CB (2000) Accumulation and long-term effects of stress in fish. The biology of animal stress: basic principles and implications for animal welfare. CABI Publishing, Wallingford, pp 147-158

Schreck CB (2010) Stress and fish reproduction: the roles of allostasis and hormesis. Gen Comp Endocrinol 165:549-556

Schreck CB, Tort L (2016) The concept of stress in fish. Fish Physiol 35:1-34

Schreck CB, Contreras-Sanchez W, Fitzpatrick MS (2001) Effects of stress on fish reproduction, gamete quality, and progeny. Aquaculture 197:3-24

Schreck C, Tort L, Farrell AP et al (2016) Biology of stress in fish. Academic Press, Cambridge

Sebastianutto L, Picciulin M, Costantini M, Ferrero EA (2011) How boat noise affects an ecologically crucial behaviour: the case of territoriality in Gobius cruentatus (Gobiidae). Environ Biol Fishes 92(2):207-215

Seehausen O, van Alphen JJM, Witte F (1997) Cichlid fish diversity threatened by eutrophication that curbs sexual selection. Science 277:1808-1811

Sertlek HÖ, Slabbekoorn H, ten Cate C, Ainslie MA (2019) Source specific sound mapping: spatial, temporal and spectral distribution of sound in the Dutch North Sea. J Environ Pollut 247:1143-1157

Shafiei Sabet S, van Dooren D, Slabbekoorn H (2016) Son et lumière: sound and light effects on spatial distribution and swimming behavior in captive zebrafish. Environ Epidemiol 212:480-488. https://doi.org/10.1016/j.envpol. 2016.02.046 
Shannon G, McKenna MF, Angeloni LM, Crooks KR, Fristrup KM, Brown E, Warner KA, Nelson MD, White C, Briggs J (2016) A synthesis of two decades of research documenting the effects of noise on wildlife. Biol Rev 91:982-1005

Sierra-Flores R, Atack T, Migaud H et al (2015) Stress response to anthropogenic noise in Atlantic cod Gadus morhua L. Aquacult Eng 67:67-76

Skaret G, Nøttestad L, Fernö A et al (2003) Spawning of herring: day or night, today or tomorrow? Aquat Living Resour 16:299-306

Skaret G, Axelsen BE, Nøttestad L, Fernö A, Johannessen A (2005) The behaviour of spawning herring in relation to a survey vessel. ICES J Mar Sci 62(6):1061-1064

Skjæraasen JE, Nash RDM, Korsbrekke K, Fonn M, Nilsen T, Kennedy J, Nedreaas KH, Thorsen A, Witthames PR, Geffen AJ, Høie H, Kjesbu OS (2012) Skipped spawning in the Northeast arctic cod. Proc Natl Acad Sci 109:8995-8999. https://doi.org/10.1073/pnas.1200223109

Slabbekoorn H (2016) Aiming for progress in understanding underwater noise impact on fish: complementary need for indoor and outdoor studies. In: Popper AN, Hawkins A (eds) The effects of noise on aquatic life II, advances in experimental medicine and biology 875 . Springer, Berlin, pp 1057-1065

Slabbekoorn H, Bouton N (2008) Soundscape orientation: a new field in need of sound investigation. Anim Behav 76:e5-e8

Slabbekoorn H, Bouton N, van Opzeeland I et al (2010) A noisy spring: the impact of globally rising underwater sound levels on fish. Trends Ecol Evol 25:419-427

Slabbekoorn H, Dooling RB, Popper AN, Fay RR (2018) Effects of anthropogenic noise on animals. Springer handbook of auditory research 66. Springer, New York

Slabbekoorn H, Dalen J, de Haan D, Winter E, Radford C, Ainslie MA, Heaney KD, van Kooten T, Thomas L, Harwood J (2019) Population level consequences of seismic surveys on fishes: an interdisciplinary challenge. In: Fish fish, pp 1-33

Smith ME, Coffin AB, Miller DL, Popper AN (2006) Anatomical and functional recovery of the goldfish (Carassius auratus) ear following noise exposure. J Exp Biol 209:4193-4202

Sprague MW, Luczkovich JJ (2012) Modeling the propagation of transient sounds in very shallow water using finite difference time domain (FDTD) calculations. In: Popper AN, Hawkins A (eds) The effects of noise on aquatic life. Advances in experimental medicine and biology. Springer, New York, pp 459-461

Stanley JA, Van Parijs SM, Hatch LT (2017) Underwater sound from vessel traffic reduces the effective communication range in Atlantic cod and haddock. Sci Rep 7:14633

Sugiura N (1978) Further analysis of the data by Akaike's information criterion and the finite corrections. Commun Stat Theory Methods A7:13-26

R Core Team (2017) R: a language and environment for statistical computing

Trivers R (1972) Parental investment and sexual selection. In: Campbell B (ed) Sexual selection and the descent of man 1871-1971. Aldine Press, Chicago, pp 139-179

Tudorache C, ter Braake A, Tromp M et al (2015) Behavioral and physiological indicators of stress coping styles in larval zebrafish. Stress 18:121-128
Vabø R, Olsen K, Huse I (2002) The effect of vessel avoidance of wintering Norwegian spring spawning herring. Fish Res 58:59-77

van der Sluijs I, Gray SM, Amorim MCP, Barber I, Candolin U, Hendry AP, Krahe R, Maan ME, Utne-Palm AC, Wagner H-J, Wong BBM (2011) Communication in troubled waters: responses of fish communication systems to changing environments. Evol Ecol 25(3):623-640

Vasconcelos RO, Amorim MCP, Ladich F (2007) Effects of ship noise on the detectability of communication signals in the Lusitanian toadfish. J Exp Biol 210:2104-2112

Vasconcelos RO, Carrico R, Ramos A et al (2012) Vocal behavior predicts reproductive success in a teleost fish. Behav Ecol 23:375-383

Vetter BJ, Cupp AR, Fredricks KT et al (2015) Acoustical deterrence of Silver Carp (Hypophthalmichthys molitrix). Biol Invasions 17:3383. https://doi.org/10.1007/s10530015-0964-6

Vetter BJ, Murchy K, Cupp AR et al (2017) Acoustic deterrence of bighead carp (Hypophthalmichthys nobilis) to a broadband sound stimulus. J Great Lakes Res 43:163-171. https://doi.org/10.1016/j.jglr.2016.11.009

Voellmy IK, Purser J, Flynn D et al (2014) Acoustic noise reduces foraging success in two sympatric fish species via different mechanisms. Anim Behav 89:191-198

Wahlberg M, Westerberg H (2005) Hearing in fish and their reactions to sounds from offshore wind farms. Mar Ecol Prog Ser 288:295-309

Wendelaar Bonga SE (1997) The stress response in fish. Physiol Rev 77(3):591-625

Williams R, Wright AJ, Ashe E et al (2015) Impacts of anthropogenic noise on marine life: publication patterns, new discoveries, and future directions in research and management. Ocean Coast Manag 115:17-24

Wilson B, Batty RS, Dill L (2004) Pacific and Atlantic herring produce burst pulse sounds. Proc B 271:S95-S97

Wingfield JC, Ramenofsky M (1999) Hormones and the behavioral ecology of stress. In: Balm PHM (ed) Stress physiology in animals. Sheffield Academic Press, Sheffield, pp 1-51

Wingfield JC, Sapolsky RM (2003) Reproduction and resistance to stress: when and how. J Neuroendocrinol 15:711-724

World Health Organization (2011) Burden of disease from environmental noise. Quantification of healthy life years lost in Europe. www.euro.who.int/en/health-topics/environmentand-health/noise/publications. Accessed 29 Feb 2020

Wright AJ (2007) Anthropogenic noise as a stressor in animals. Int J Comp Psychol 20:250-273

Wysocki L, Ladich F (2005) Effects of noise exposure on click detection and the temporal resolution ability of the goldfish auditory system. Hear Res 201:27-36

Zeyl JN, Malavasi S, Holt DE et al (2016) Convergent aspects of acoustic communication in darters, sculpins, and gobies. In: Popper AN, Hawkins A (eds) The effects of noise on aquatic life II, advances in experimental medicine and biology 875 . Springer, Berlin, pp 93-120

Publisher's Note Springer Nature remains neutral with regard to jurisdictional claims in published maps and institutional affiliations. 